\title{
Multi-Mission Capable, High g Load mW RPS
}

\section{Final Report}

\author{
May 2007 \\ Prepared by
}

John C. Bass, Nathan Hiller, Velimir Jovanovic and Norbert B. Elsner HZ-Z Report No. 6100

For

Instrument No. DE-FG07-06ID14755

U.S. Department of Energy

Office of Space \& Defense Power Systems

NE-50/Germantown Bldg 1000 Independence Ave., SW

Washington, DC 20585-1290 


\section{$\underline{\text { Summary }}$}

Over the past few years $\mathrm{Hi}-\mathrm{Z}$ has been developing a wide range of $\mathrm{mW}$ generators and life testing thermoelectric modules for the Department of Energy (DOE) to fulfill requirements by NASA Ames and other agencies. The purpose of this report is to determine the capabilities of a wide range of $\mathrm{mW}$ generators for various missions.

In the $1^{\text {st }}$ quarterly report the power output of various $\mathrm{mW}$ generators was determined via thermal and mechanical modeling. The variable attributes of each generator modeled were: the number of RHUs $(1-8)$, generator outer diameter (1.25 - 4 in.), and G-load (10, 500, or 2,000). The resultant power output was as high as $180 \mathrm{~mW}$ for the largest generator with the lowest Gload.

Specifically, we looked at the design of a generator for high $G$ loading that is insulated with Xenon gas and multifoil solid insulation. Because the design of this new generator varied considerably from the previous generator design, it was necessary to show in detail how it is to be assembled, calculate them as of the generator and determine the heat loss from the system. A new method of assembling the RHU was also included as part of the design.

As a side issue we redesigned the test stations to provide better control of the cold sink temperature. This will help in reducing the test data by eliminating the need to "normalize" the data to a specific temperature. In addition these new stations can be used to simulate the low ambient temperatures associated with Mars and other planets.

\section{Background}

NASA's plans for some future space mission calls for one or more small distributed radioisotope thermoelectric generators (RTGs). The payoffs are:

- $\quad$ more reliability and less complexity in designing power systems

- $\quad$ some missions only require mWs of power

$\mathrm{Hi}-\mathrm{Z}$ has been developing a wide range of $\mathrm{mW}$ generators and life testing thermoelectric modules for the DOE and other agencies over the past few years.

The Hi-Z $40 \mathrm{~mW}$ generator (Fig. 1), developed under previous DOE contracts, converts heat of a $1 \mathrm{~W}_{\mathrm{t}}$ RHU shown in Figure 2 into $\sim 40$ $\mathrm{mW}$ of electrical power using a small $\mathrm{Bi}_{2} \mathrm{Te}_{3}$ thermoelectric module. The heat balance of the generator is such that the module hot side and RHU are maintained at $250^{\circ} \mathrm{C}$. At this temperature a significant amount of heat escapes the generator via

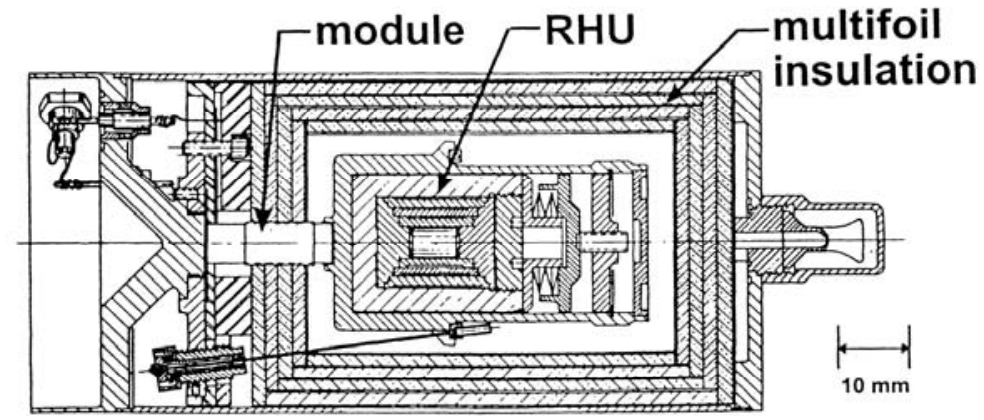

Figure 1. Layout of Flight System MRPS. 


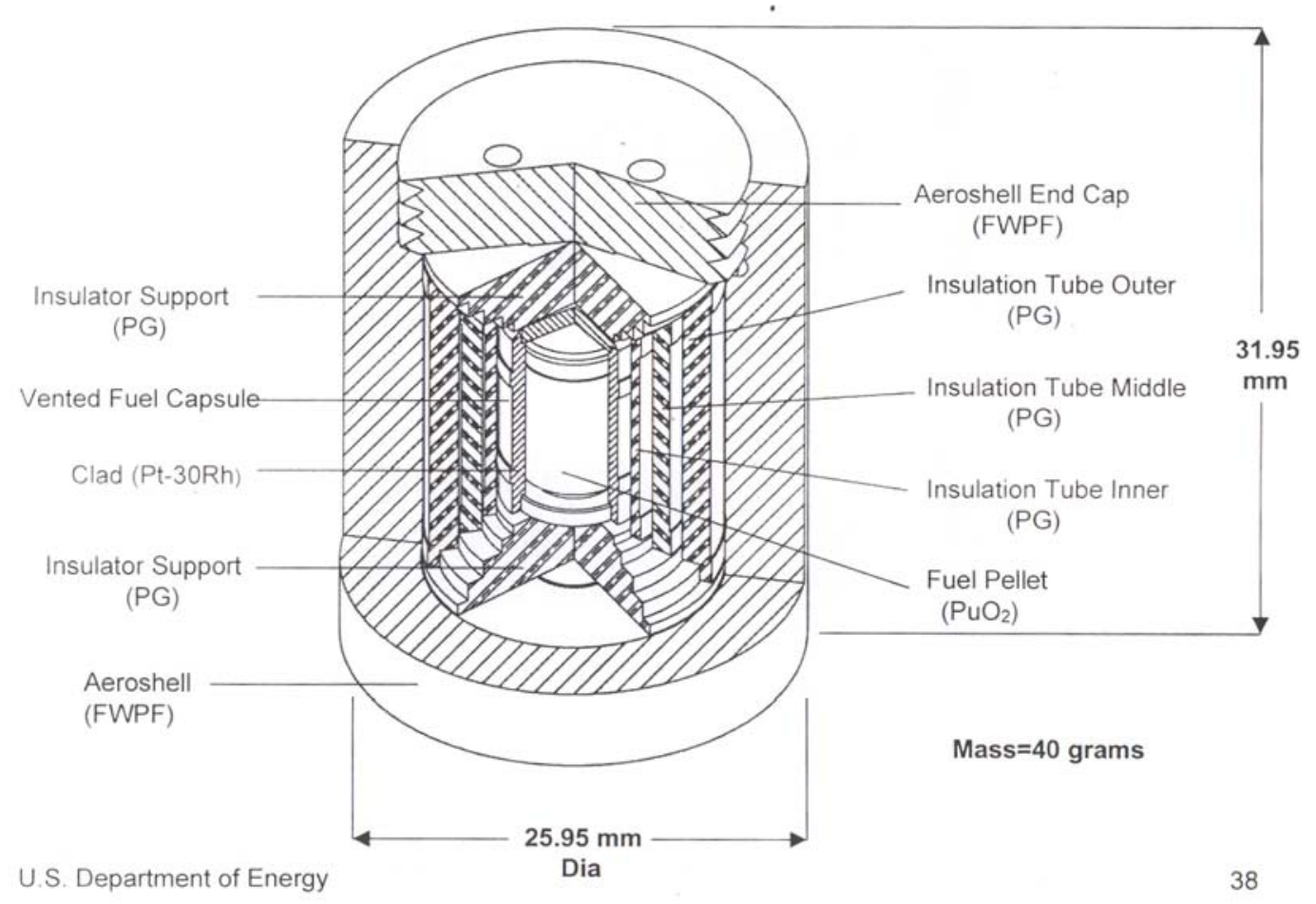

Figure 2. 1 Watt Radioisotope Heater Unit (RHU)

radiation. To prevent this radiation heat loss, multilayered radiation shields are wrapped around the fuel capsule and module. For the radiation shields to be effective they must exist in a reasonable vacuum $(<5$ mtorr $)$.

The $40 \mathrm{~mW}$ generator concept is an out growth of the earlier $75 \mathrm{~mW}$ generators that used $4.5 \mathrm{~W}_{\mathrm{t}}$ of $\mathrm{PuO}_{2}$ and operated successfully for $\sim 10$ years in a terrestrial application. A Hi-Z - JPL STTR initiated the original concept using only a $1 \mathrm{~W}_{\mathrm{t}}$ heat source. DOE assumed funding of multi-year program and had Hi-Z continuously interacting with NASA to determine their requirements. NASA took over the program in 2004 and DOE selected Hi-Z for a further design study which is the purpose of this program.

\section{$\underline{\text { Generator Model }}$}

A three dimensional thermal model of the high G-load generator (Fig. 3) selected in Reference 1. The heat source used in this model is $1 \mathrm{~W}$ Light Weight Radioisotope Heater Unit (RHU) ${ }^{(2)}$ A constant insulation thickness was used to envelope the fuel capsule and the module length is equal to the insulation thickness in all cases considered. The specific generator attributes are listed in the tables below: 


\begin{tabular}{|l|l|}
\hline Module & \\
\hline & \\
\hline Seebeck $(\mathrm{mV} / \mathrm{K})$ & 0.171 \\
& \\
\hline $\mathrm{k}(\mathrm{W} / \mathrm{cm} . \mathrm{K})$ & 0.015 \\
\hline
\end{tabular}

\begin{tabular}{|l|c|}
\hline Fuel Capsule & \\
\hline RHU heat (W) & 1 \\
& \\
\hline \# of RHUs & Variable (1-8) \\
\hline
\end{tabular}

\begin{tabular}{|l|l|}
\hline Insulation & \\
\hline & \\
\hline $\mathrm{k}(\mathrm{W} / \mathrm{cm} \cdot \mathrm{K})$ & 0.00007 \\
& To \\
& 0.00014 \\
\hline
\end{tabular}

\begin{tabular}{|l|l|}
\hline Support Wires & \\
\hline & \\
\hline$\sigma_{\mathrm{y}}(\mathrm{psi})$ & $1.2 \times 10^{5}$ \\
\hline $\mathrm{k}(\mathrm{W} / \mathrm{cm} . \mathrm{K})$ & 0.07 \\
\hline Orientation factor & 1.057 \\
\hline
\end{tabular}

\begin{tabular}{|l|c|}
\hline Generator Requirements & \\
\hline Vo at $\Delta \mathrm{T}=225 \mathrm{C}(\mathrm{V})$ & 12 \\
\hline Factor of safety & 1 \\
\hline Dynamic load factor & 1 \\
\hline G load & 10,500, or 2,000 \\
\hline Diameter (in.) & Variable $(1.2-4)$ \\
\hline
\end{tabular}

* varies to fit \# of RHUs used in case.

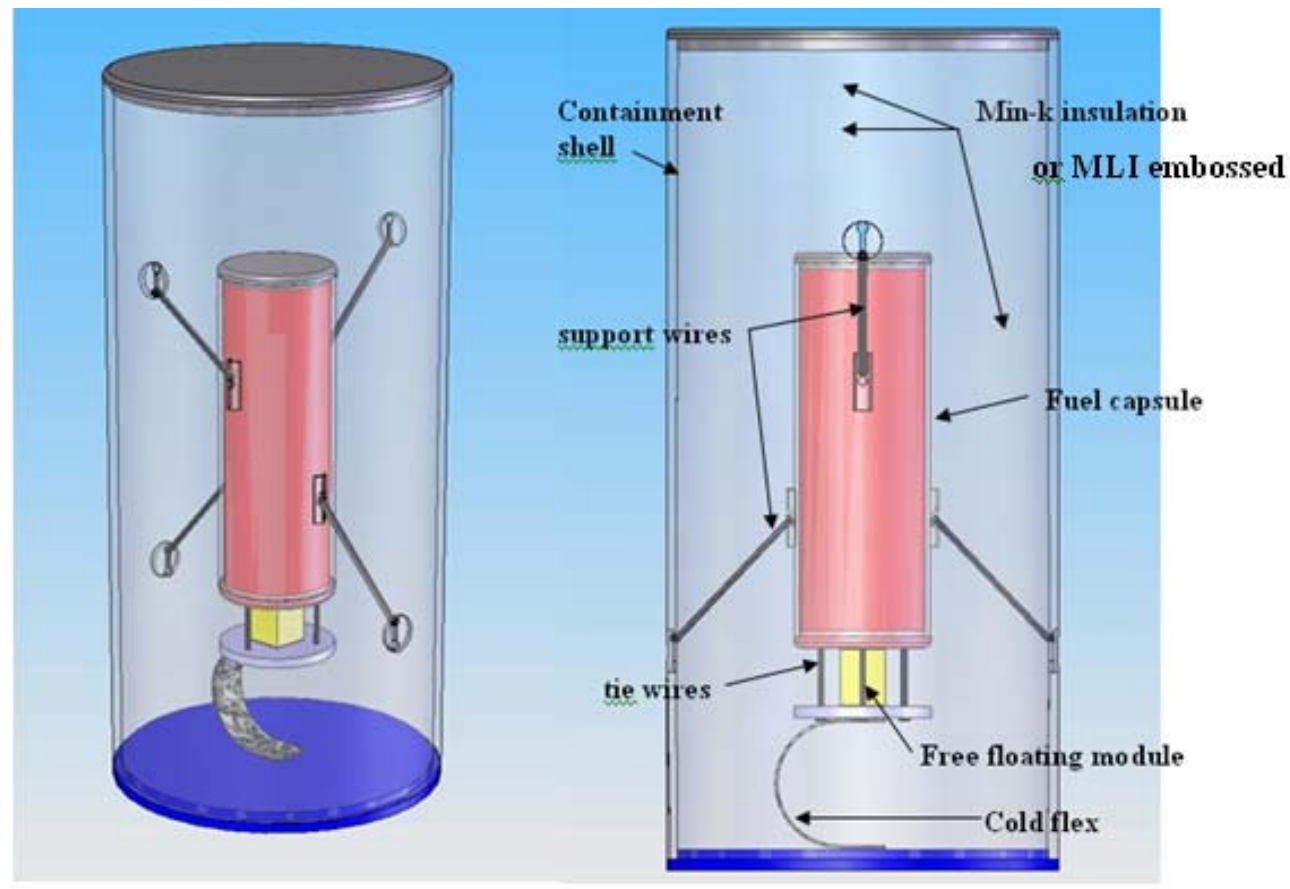

Figure 3. An analytical three dimensional thermal model of the high Gload generator.

The "orientation factor" takes into account the worst case generator impact angle. This factor was calculated by determining the wire tensions on the configuration shown in Figure 4 for all impact orientations.

The thermal conductivity was calculated by matching the power from the 3-D thermal model to the power measured by the $40 \mathrm{~mW}$ generator (figure 1, AKA Unit \# 4) with Xenon backfill at $1 \mathrm{~atm}$. The raw data for Unit \# 4 is:

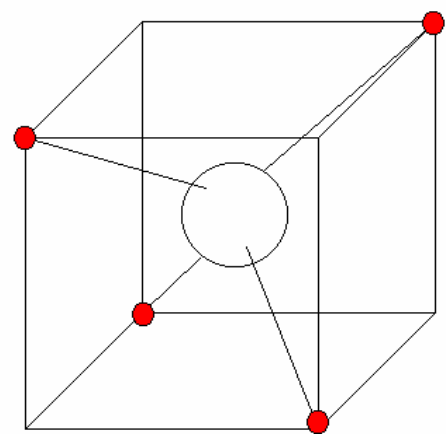

Figure 4. An analytical three dimensional thermal model of the high G-load generator. 


\section{Power in (W) $\quad$ Power out $(\mathrm{mW})$}

$1.1 \quad 10.25$

$3.2 \quad 45$

These values are actually and 3.1 after subtracting for 0.1 heat loss from heater wires. The results of this power matching or k matching is shown in table below and compared with other MLI and xenon data for comparison

Table 1. The thermal conductivity was calculated by matching the power from the 3-D thermal model to the power measured by the $\mathbf{4 0} \mathrm{mW}$ generator.

The results of this power matching or $\mathrm{k}$ matching is shown in this table and compared with other MLI and xenon data.

\begin{tabular}{|l|r|r|r|}
\hline Insulation Configuration & $\mathbf{T}_{\mathbf{c}}(\mathbf{C})$ & $\mathbf{T}_{\mathbf{h}}(\mathbf{C})$ & $\mathbf{k} \cdot \mathbf{1 0}^{\mathbf{5}} \mathbf{( W / c m . K )}$ \\
\hline & & & \\
\hline 1. No MLI (radiation calc. for Unit \#4, $\left.\varepsilon_{1}=\varepsilon_{2}=0.03\right)$ & 25 & 250 & $\sim 3.1$ \\
\hline 2. MLI in vacuum (standard data for no slits) & -195 & 300 & $\sim 0.1$ \\
\hline 3. MLI in vacuum (Unit \# 4 generator with slits) & 25 & 250 & 0.9 \\
\hline & & & 6.0 \\
\hline \multirow{2}{*}{ 4. Xenon gas (standard data) } & 25 & 25 & 7.5 \\
\cline { 2 - 4 } & 25 & 250 & 7.2 \\
\hline \multirow{3}{*}{ 5. MLI in Xenon (Unit \# 4 generator) } & 25 & 26 & 8.1 \\
\cline { 2 - 4 } & 25 & 135 & 14.7 \\
\cline { 2 - 4 } & 25 & 250 & \\
\end{tabular}

In entry 1 the effective $\mathrm{k}$ was calculated using the heat loss by radiation assuming $\mathrm{e}_{1}=\mathrm{e}_{2}=0.3$. Although $\mathrm{k}$ is not used for radiation it was used here for comparative purposes only.

Although the $\mathrm{k}$ for MLI is highly dependent on layer density, thickness, temperature, and gas pressure, the typical values are stated in entry 2 for comparison reasons.

Entry 3 is determined using the matching model technique. Note that it is more than entry 2 and less than entry 1, as expected, however one would expect it to be much lower than entry one. This high $\mathrm{k}$ is probably due to the low conductance of the MLI and generator resulting in a significant backpressure.

Entry 4 is standard data on Xenon at the Unit \# $4 \mathrm{~T}_{\mathrm{h}}$ and $\mathrm{T}_{\mathrm{c}}$.

Entry 5 is determined using the matching $\mathrm{k}$ technique for the Unit \# 4 generator. Note that the $\mathrm{k}$ value is $\sim$ to the standard $\mathrm{k}$ values for Xenon at low generator temperatures where radiation is minimal, and $\mathrm{k}$ significantly increases as the generator $\mathrm{T}_{\mathrm{h}}$ increases as expected because radiation becomes significant. Also note that to calculate $\mathrm{k}=7.2$ in entry $5 \mathrm{I}$ had to subtract out the module heat and wire heat from Q vs $\Delta \mathrm{T}$ curve then I looked at slope at Power $\sim 0$ and delta $\mathrm{T} \sim$ 0 . This slope is used in the model to get $\mathrm{k}=7.2$. The values in entry five were used to get a curve fit that relates $\mathrm{k}$ and $\Delta \mathrm{T}$ as shown in Figure 5. 


\section{3-D Generator Model Results}

Using the effective thermal conductivity values (Fig. 5) determined for the Xenon/MLI insulated Unit \#4 generator, the power, module size, leg size, and $\Delta \mathrm{T}$ were calculated for various generator diameters, \# of RHUs, and $G$ loads as shown in Figures $6-10$. Note that the same amount of space is used at the top of the fuel capsule to control RHU pressure and outgassing, is used for all modeling. The numbers located at the ends of each curve represent the $\mathrm{G}$ load.

Note that in Figure 6 the black circle indicates the measured power produced by the unit 4 generator backfilled with Xenon/MLI. Although this point

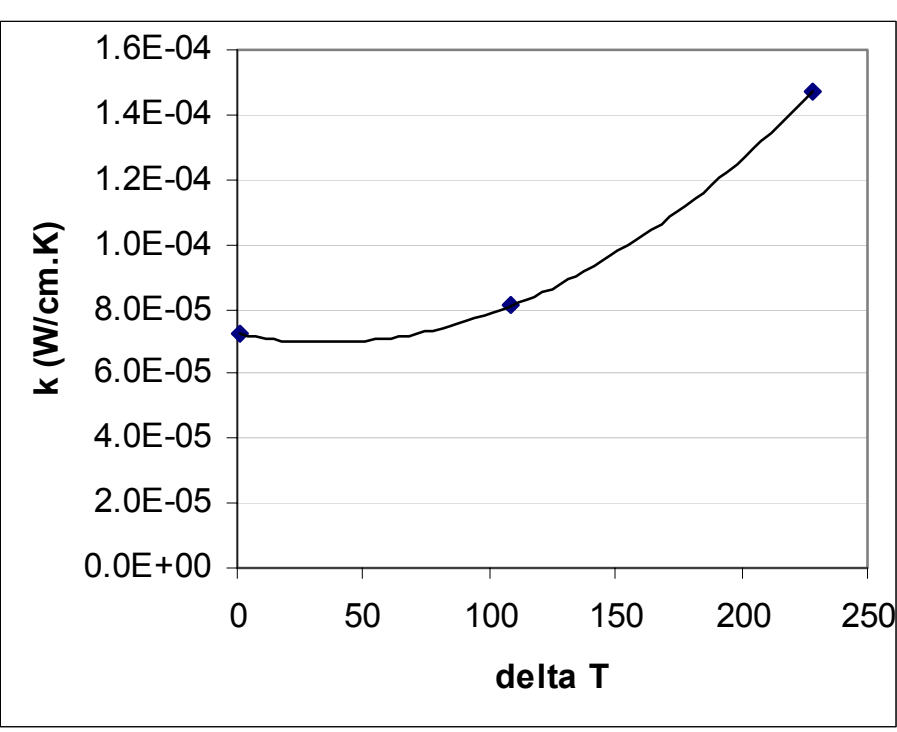

Figure 5. Resulting $k$ values vs delta $T$ for the $k$ matching process using the analytical three dimensional thermal model of the high G-load generator.

should not necessarily coincide with the curves produced by the model because there are some differences between them, it shows that the model and experimental work are in the same ballpark.

Figures 10-14 are a collection of specific attributes of Figures 5-10. Figures 11, 12, 13, 14, and 15 show $\Delta \mathrm{T}$, power, power/RHU, module width, and leg width, respectively. 

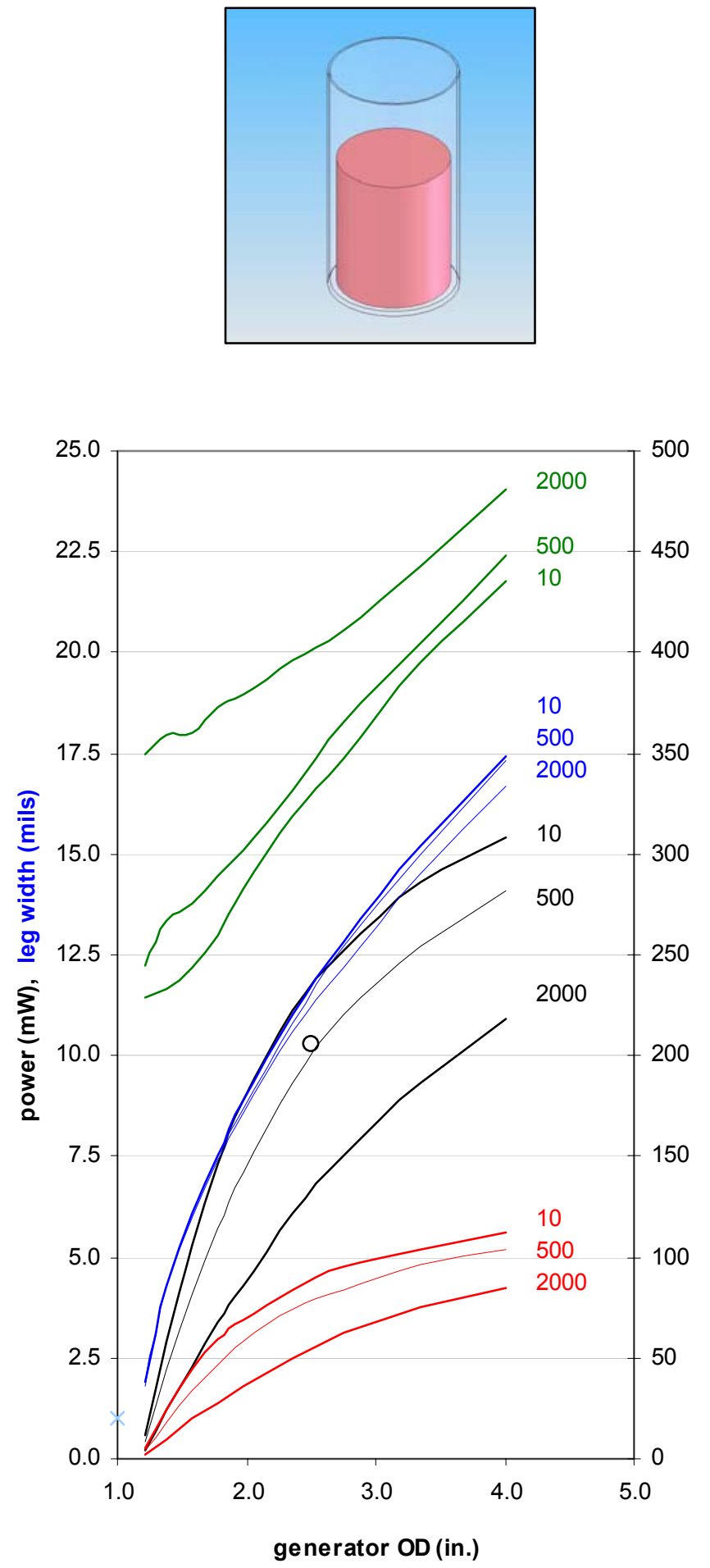

Figure 6. Results of the analytical three dimensional thermal model of the high G-load generator for the 1 RHU case.
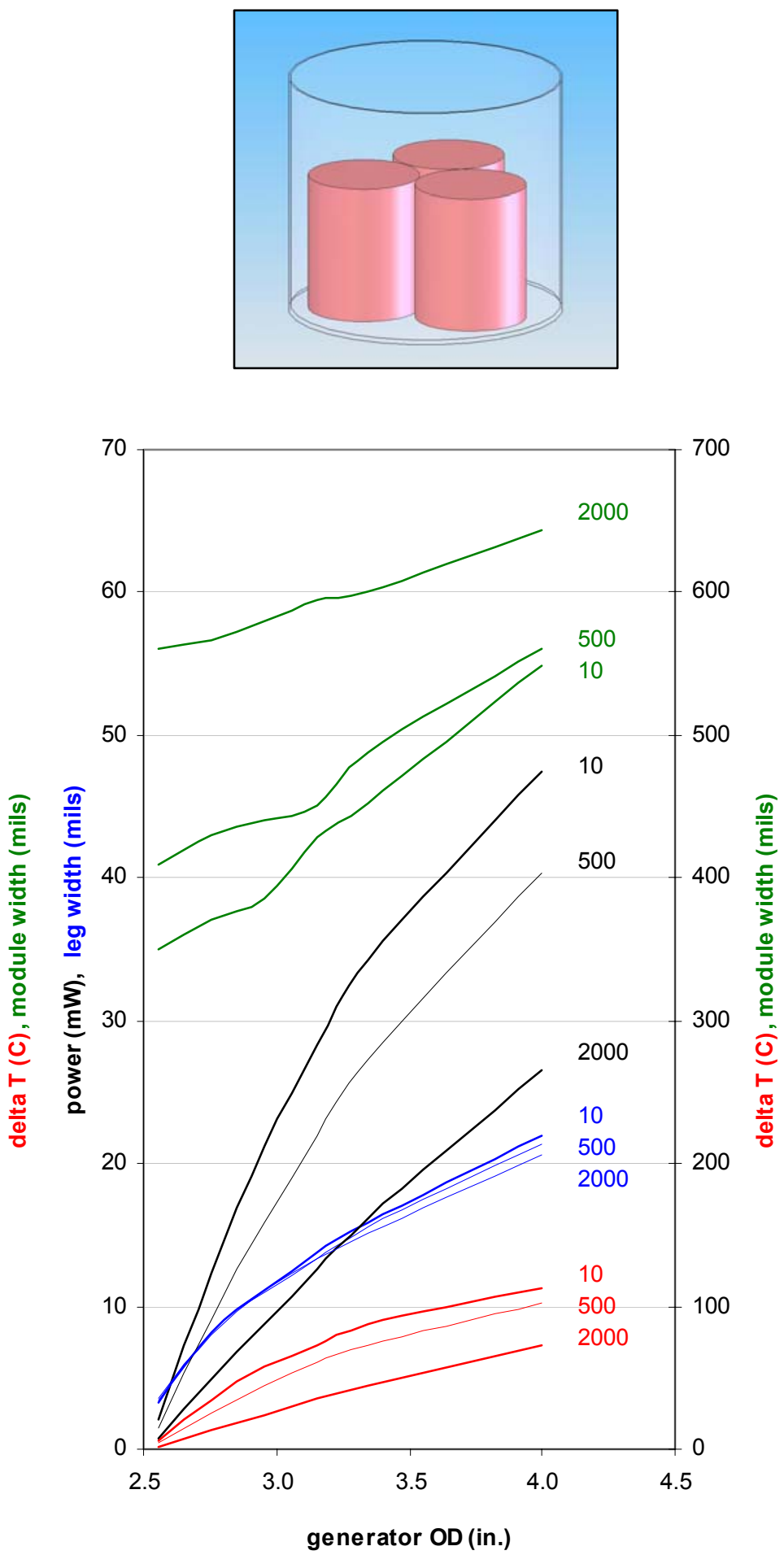

Figure 7. Results of the analytical three dimensional thermal model of the high G-load generator for the 3 RHU case. 

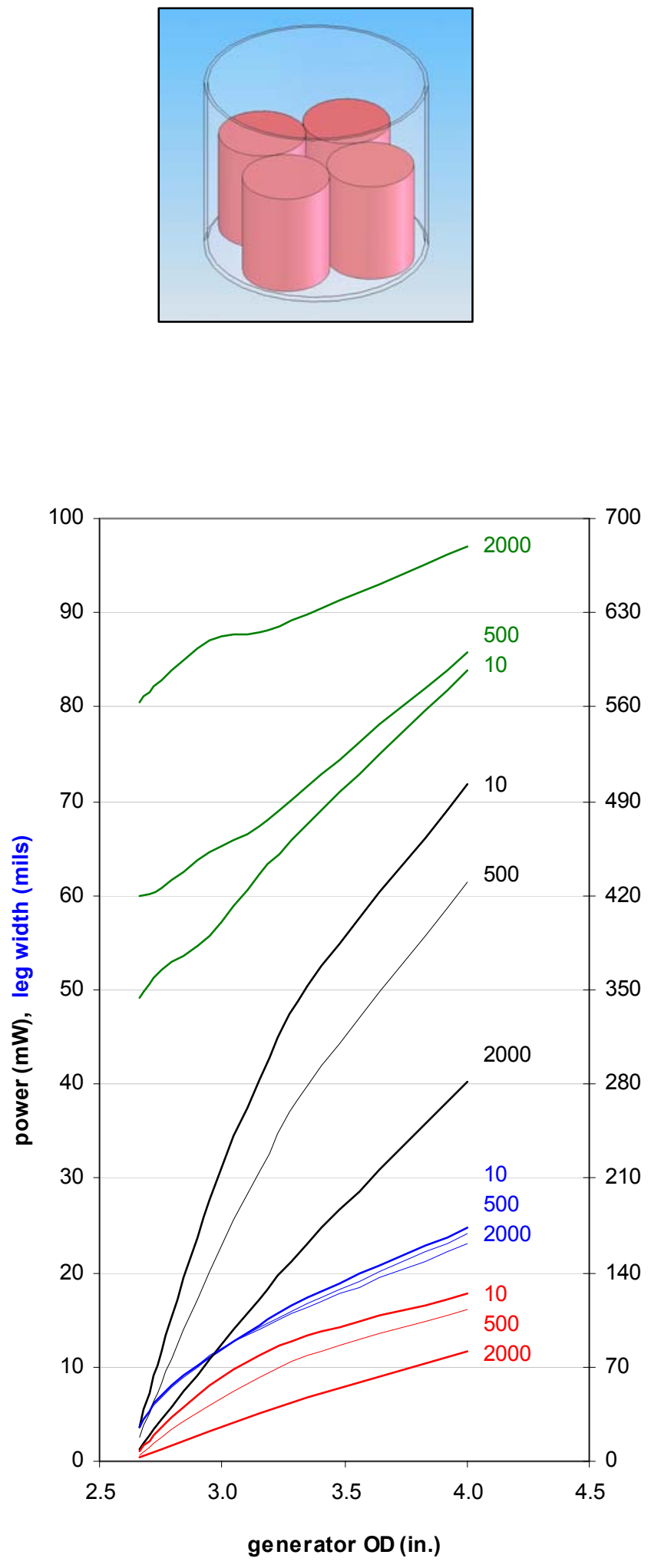

Figure 8. Results of the analytical three dimensional thermal model of the high G-load generator for the $\underline{4 \mathrm{RHU}}$ case.
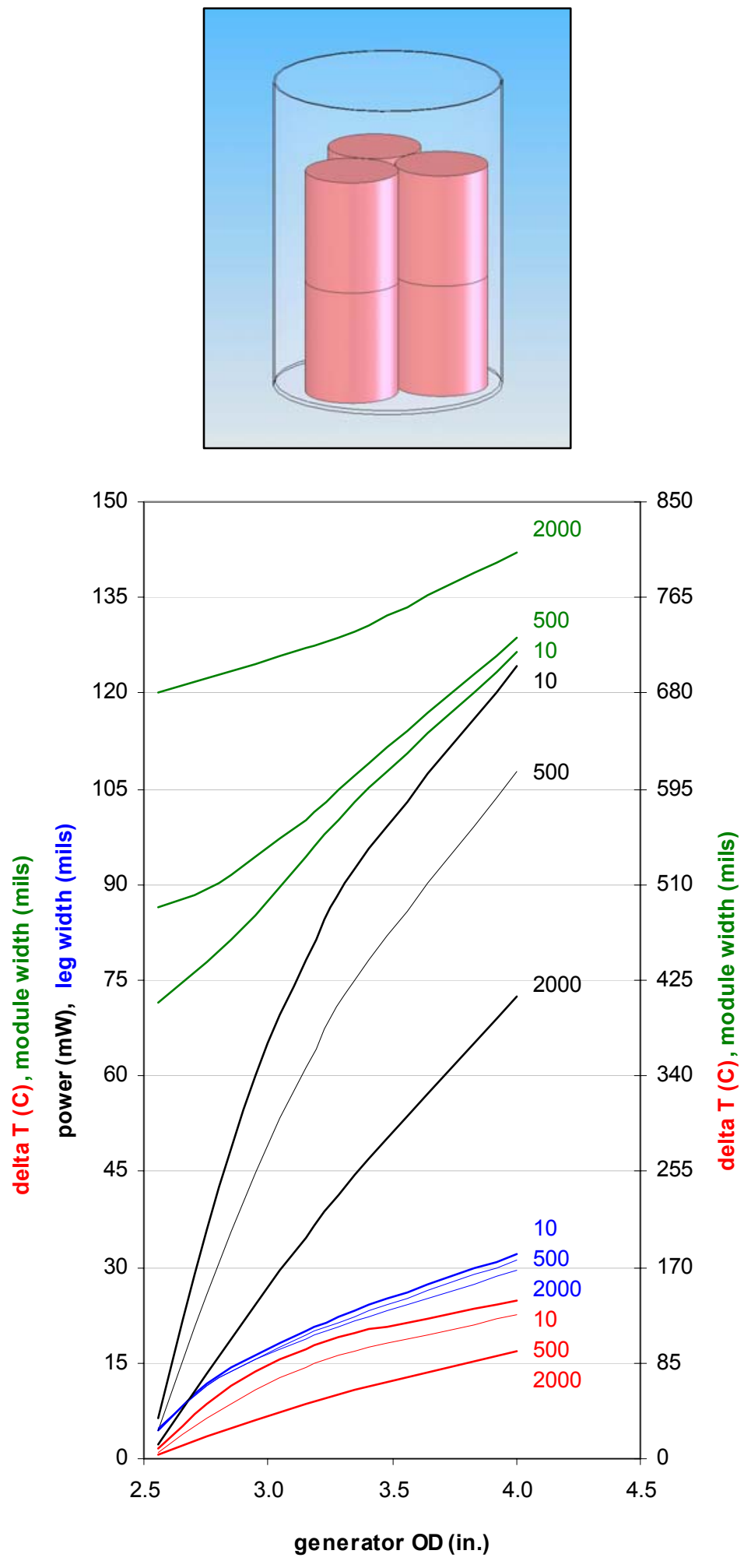

Figure 9. Results of the analytical three dimensional thermal model of the high G-load generator for the 6 RHU case. 

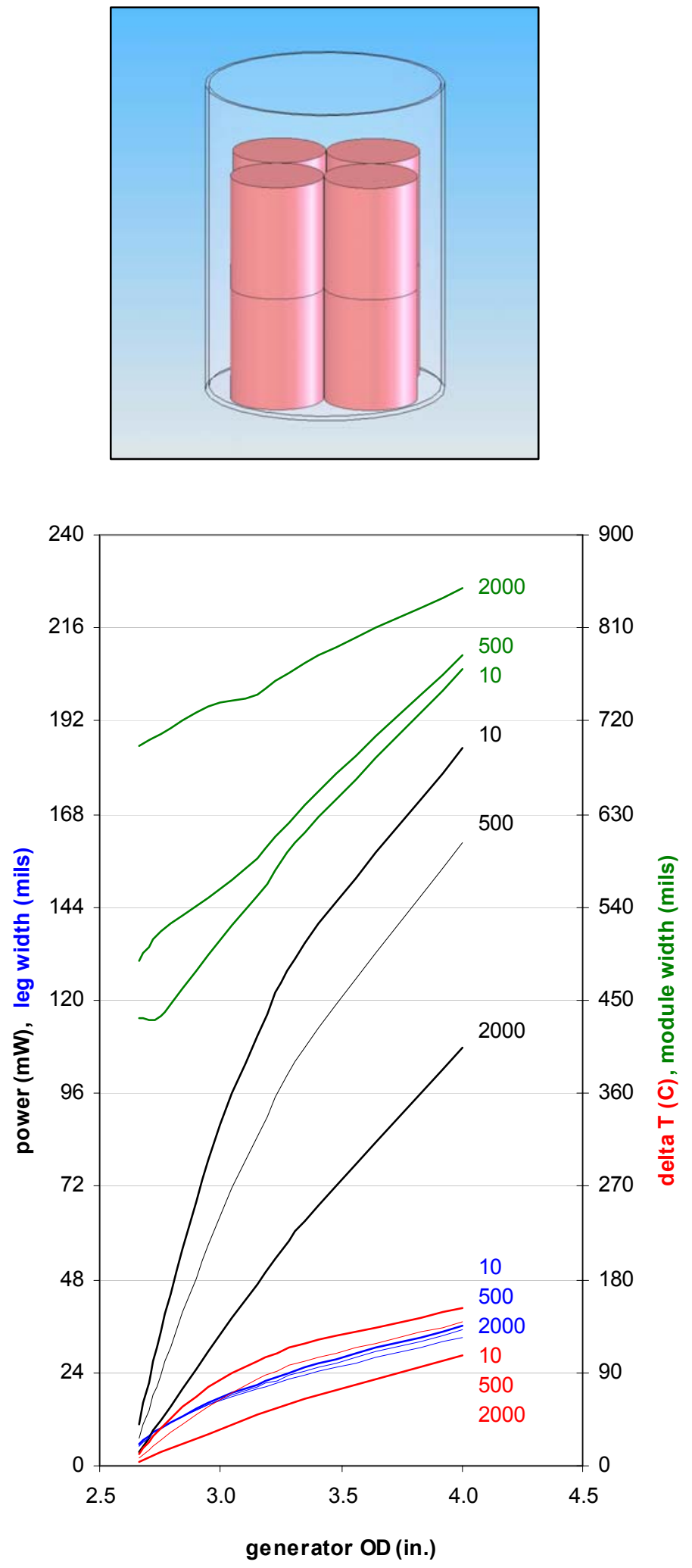

Figure 10. Results of the analytical three dimensional thermal model of the high G-load generator for the $8 \mathrm{RHU}$ case. 

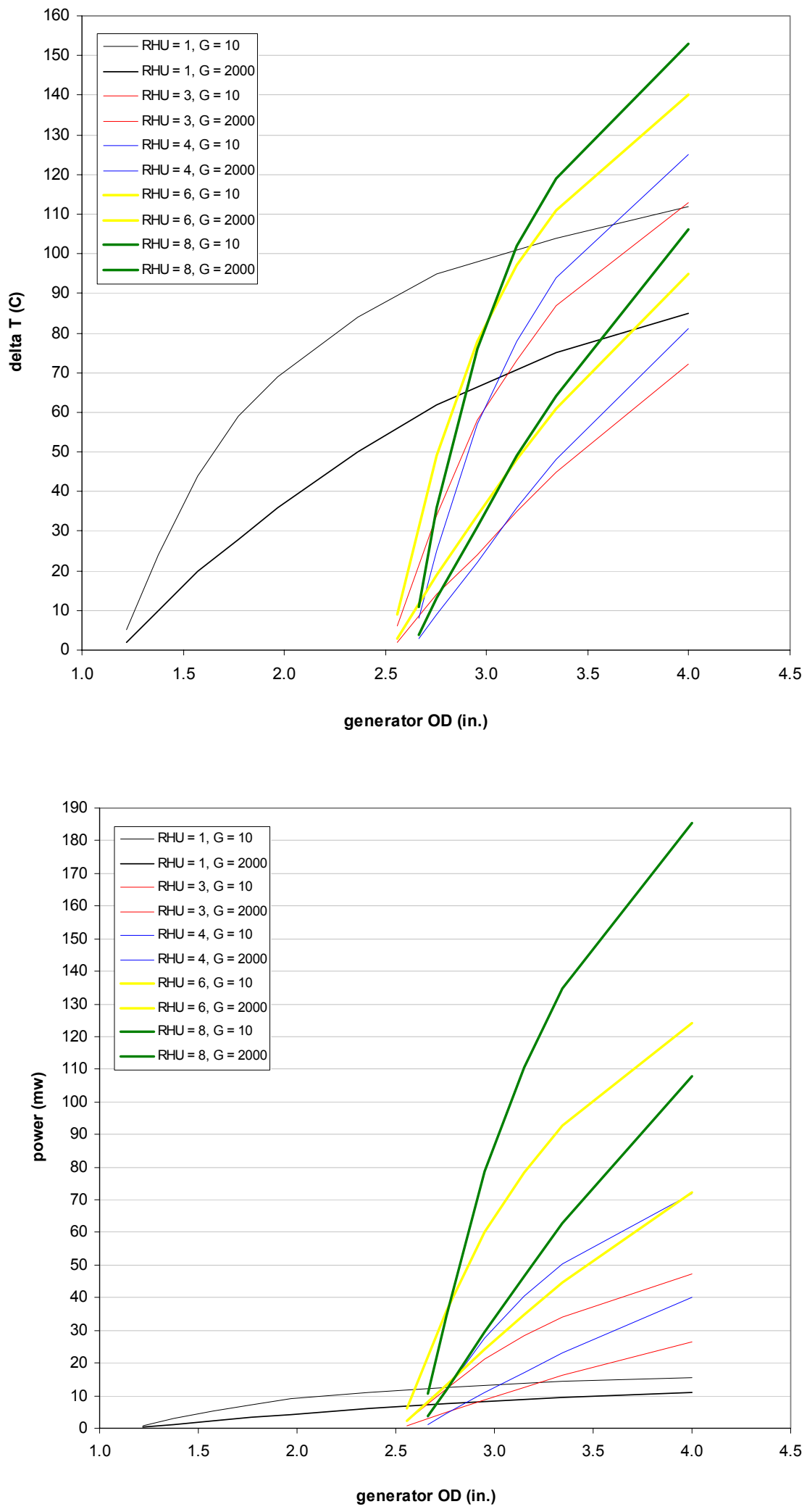

Figure 11.

$\Delta T$ vs. generator OD for various numbers of RHUs. Except for the module, the upper and lower curves represent the 10 and 2,000 G-load cases, respectively.
Figure 12.

Power vs. generator OD for various numbers of RHUs. The upper and lower curves represent the 10 and 2,000 G-load cases, respectively. 

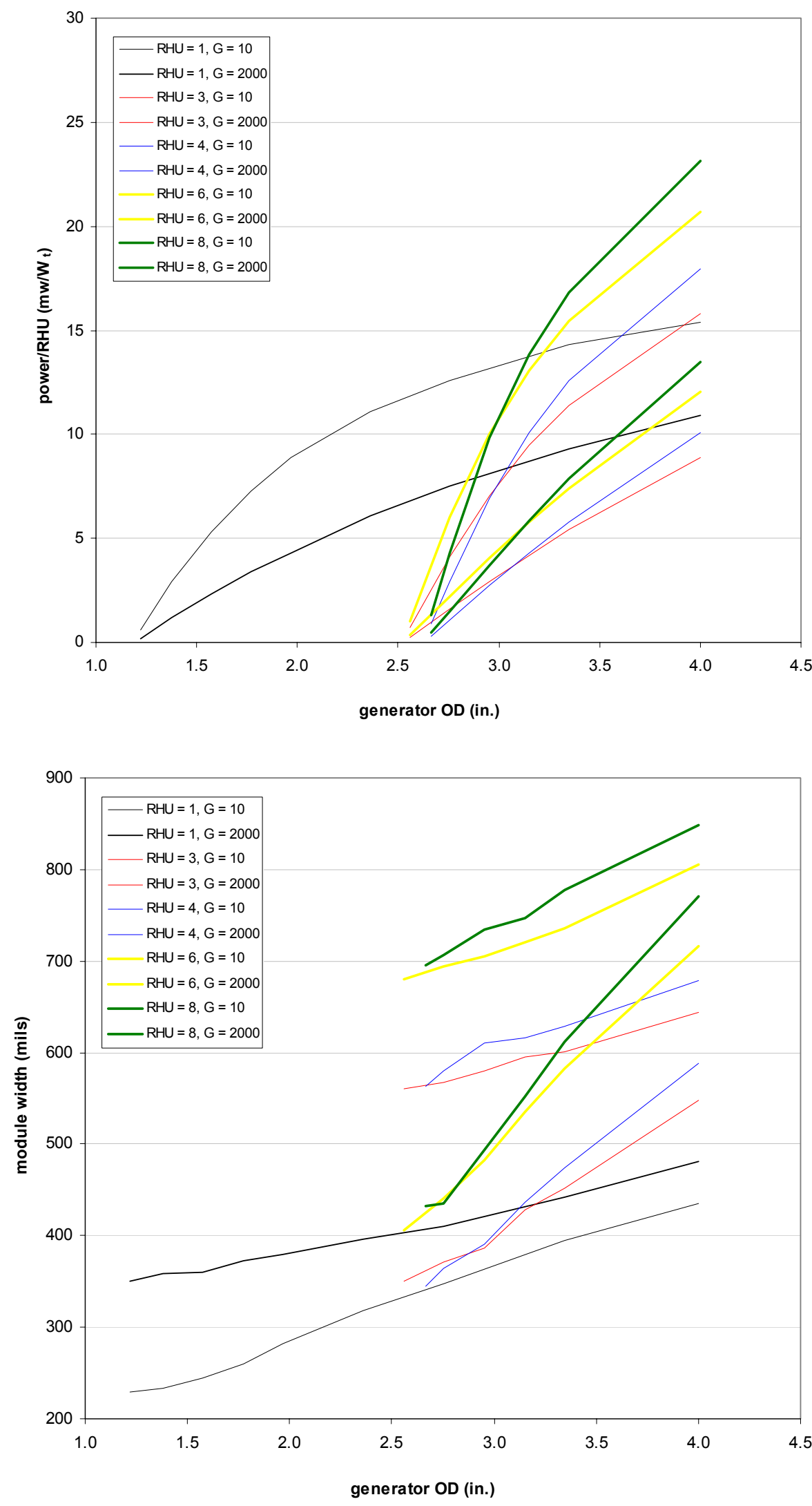

Figure 13.

Power/RHU vs. generator OD for various numbers of RHUs. The upper and lower curves represent the 10 and 2,000 G-load cases, respectively.
Figure 14.

Module width versus generator OD for various numbers of RHUs. The upper and lower curves represent the 2,000 and $10 \mathrm{G}$-load cases, respectively. 


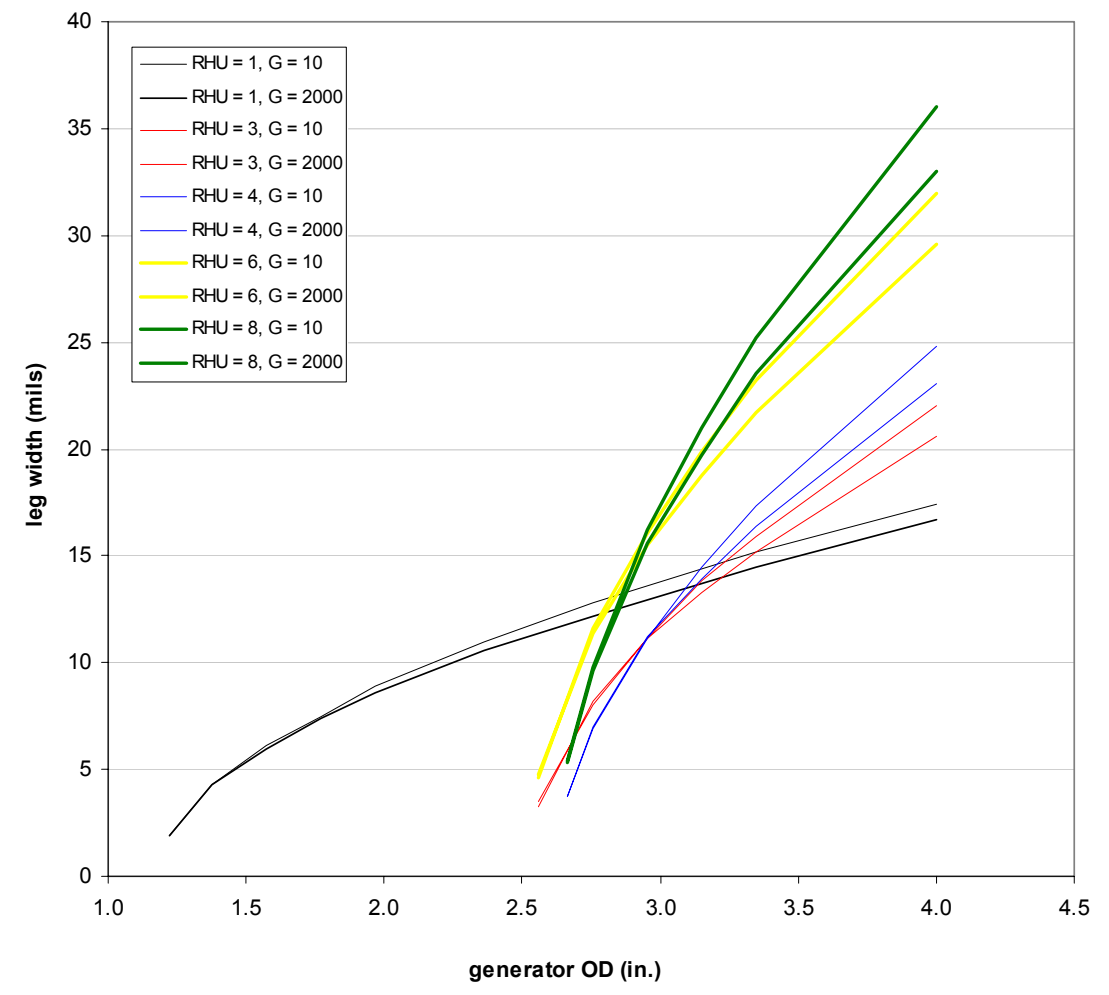

Figure 15. Leg width vs. generator OD for various numbers of RHUs. The upper and lower curves represent the 10 and 2,000 Gload cases, respectively.

\section{Modifications Required Obtaining a Higher Power RHU}

The original design of the $40 \mathrm{~mW}$ generator was based on the use of a single $1 \mathrm{~W}$ RHU package as shown in the assembly drawing presented in Figure 2. The heat source is derived from a $1 \mathrm{~W}$ $\mathrm{PuO}_{2}$ fuel pellet shown in Figure 16. The question is: How do you fabricate $\mathrm{mW}$ type generators of higher power using the technology developed during the program and field those generators without the necessity of re-qualifying the RHU?

For the 2 Watt case, Hi-Z looked at several approaches. The first approach and probably the most straight forward is to use 2 individual $1 \mathrm{~W}$ RHU's complete with aeroshell, stacked one on top of each other as shown in Figure 17. The generator design in this case is one of the original designs made for moderate $\mathrm{G}$ loadings.

A second approach would be to take two $1 \mathrm{~W} \mathrm{PuO}_{2}$ fuel pellets from Figure 16 and place them side by side in single new graphite thermo shields and aeroshell. The design for this generator was not completed because the radial heat losses were too high and the size of the generator was large.

A third approach would be to take two $1 \mathrm{~W}$ fuel pellets from Figure 16 and place them end to end in single new graphite thermo shields and aeroshell. This fuel capsule is shown in Figure 18 and 19 . 


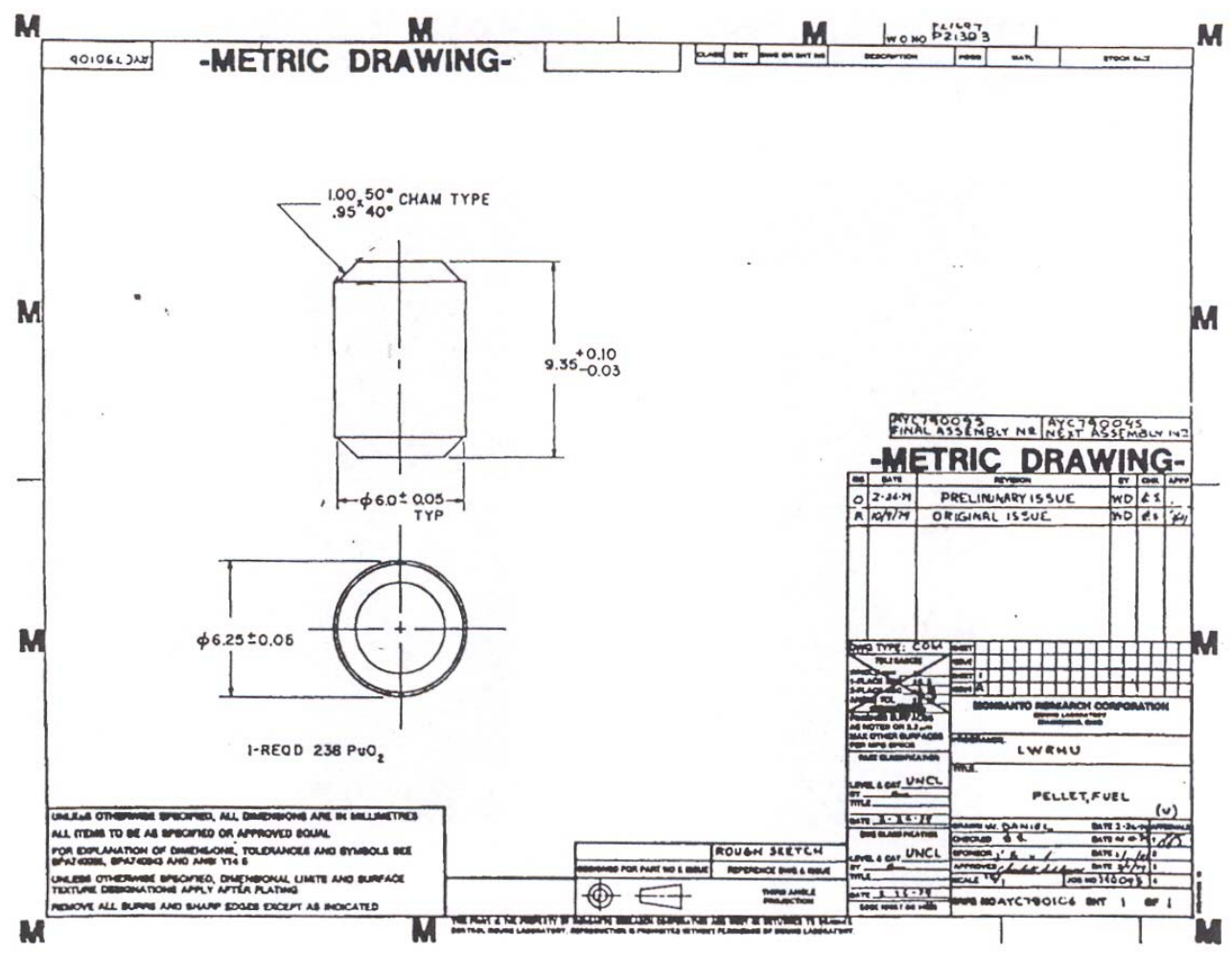

Figure 16. 1 Watt Fuel Pellet and Clad

Figure 17. Design of Generator with Two 1 Watt RHU Capsules. Insulation not shown.

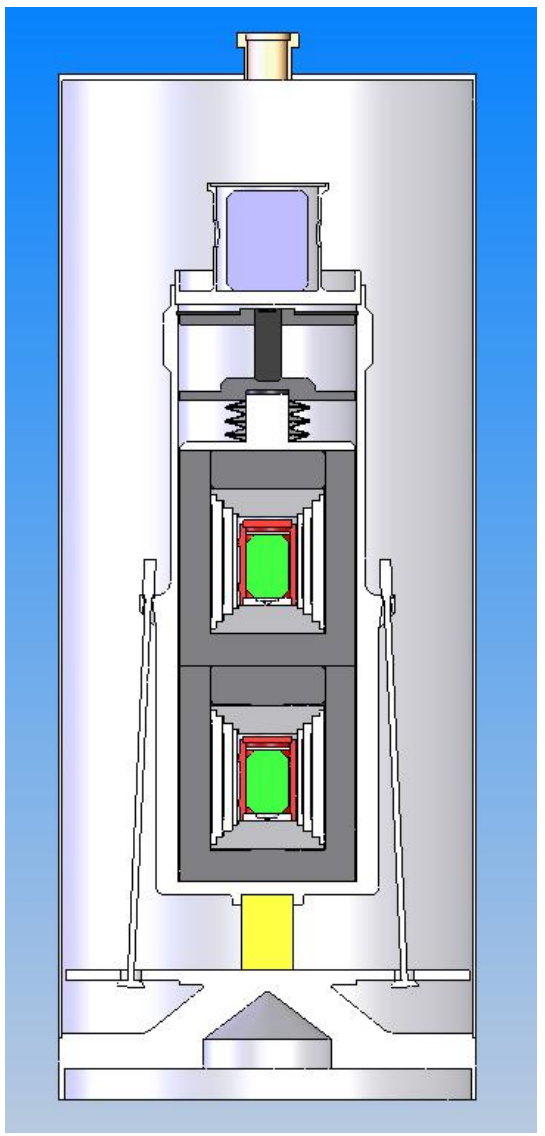


Figure 18. Fuel pellets and radial shields for 2 Watt RHU

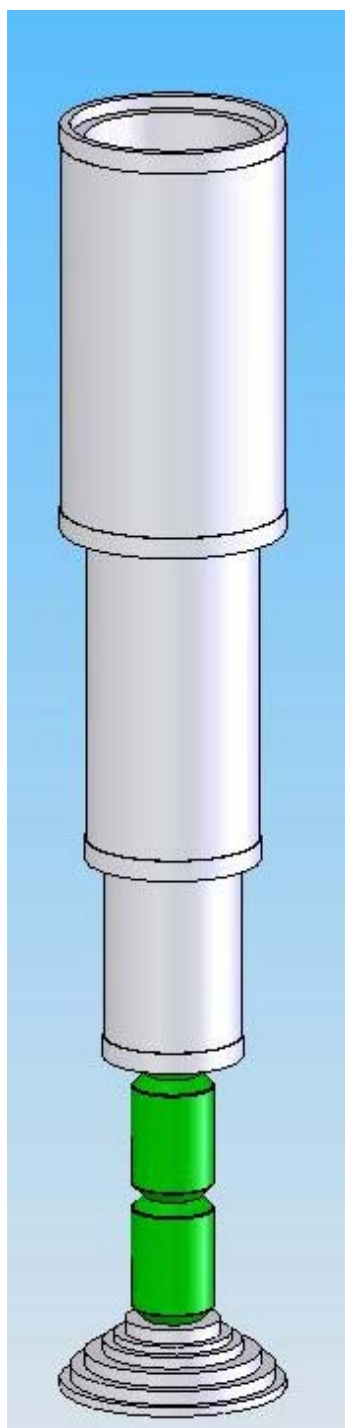

Figure 19.

Completed 2 Watt RHU

A fourth approach is to design new $\mathrm{PuO}_{2}$ fuel pellets with the same aspect (A/L) ratio $(3.02 \mathrm{~mm})$ as the original $1 \mathrm{~W}$ pellet and increase its volume as required for higher heat loads as shown in the graphs of Figures 21, 22 and 23. The new fuel pellets would be housed in new graphite thermal shields and aeroshell. This approach would require all new tooling and fabrication for all parts.

As stated previously the use of two $1 \mathrm{~W}$ RHU's is probably the most straight forward way of making a $2 \mathrm{~W}$ heat source for milliwatt generators as shown in Figure 17. This approach might be used in power sources for generators of up to $3 \mathrm{~W}$, however, the fuel capsule holder heat losses increase as the capsule holder becomes longer due to both the increased length of the capsule holder and the tortuous heat flow path and multiple interfaces. The shock and vibration problems also increase because of the higher center of gravity (CG).

To minimize these problems, we looked at approaches 2 and 3. In approach 2, the center of gravity is lower; however, the larger diameter of the RHU increases the radial heat loss through the side of the generator, which results in more insulation and a larger pressure shell. A 
preferred arrangement to obtain $2 \mathrm{~W}$ of heat would be approach 3 in which two fuel pellets are stacked on top of each other within a single clad and set of graphite thermal shields and aeroshell as shown in Figure 20. This approach can be used for possibly up to $4 \mathrm{PuO}_{2}$ pellets stacked on each other. Over 4 pellets, the heat transfer down the stack and in the thermal shields and aeroshell can become a problem.

The advantage of this stacked pellet approach is that one can use the same dies to fabricate the $\mathrm{PuO}_{2}$ fuel pellet that were used to fabricate the $1 \mathrm{~W}$ RHU. It is assumed that the fuel pellet die is the most expensive single piece of tooling.

The remaining graphite components will have to be made from new drawings, but the change required only involves making the aeroshell and thermal shields longer than the original RHU components, the diameter remains the same.

A drawing of the concept for the new milliwatt generator with a revised $2 \mathrm{~W}$ RHU is shown in Figure 20. This concept is for high shock and vibration loadings. One will

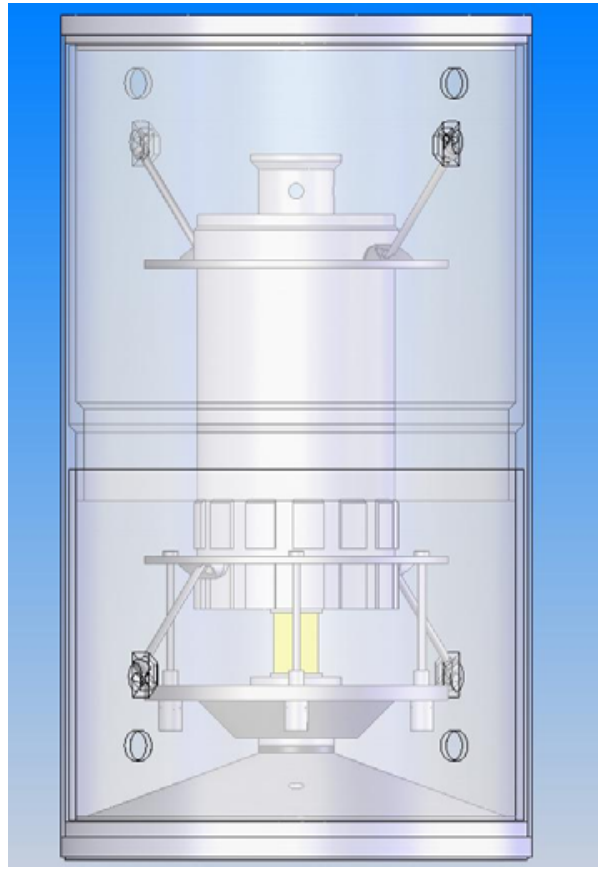

Figure 20. Design of Hi G Load Generator with Single 2 Watt RHU note that the fuel capsule which contains the $2 \mathrm{~W}$ RHU is suspended by four wires (two on top and two below) and the thermoelectric module is suspended from the bottom of the fuel capsule by four separate wires. The heat that is rejected from the module is transferred through a high thermal conductivity graphite felt pad which is located between the module and the base of the generator. This allows some relative movement between the end of the thermoelectric module and the base during high shock situations without imposing a lateral load on the module.

The advantage of this generator design approach is that the load of the heavier fuel capsule is not taken by the thermoelectric module during shock loads. The thermoelectric module only has to support its own mass, the mass of the cold sink piece and the force applied to it by the mass of the module heat sink.

Another approach to the multi-watt RHU was discussed briefly as alternative four. In this approach, a new fuel pellet would be made with the same aspect $(\mathrm{A} / \mathrm{L})$ ratio $(3.02 \mathrm{~mm})$ as the original pellet. All of the other components would have to be redesigned to accept the new pellets. Figure 21 is a graph which presents what the volume of the resulting fuel pellet would be for this case as a function of thermal power while Figure 22 presents the dimensions of the fuel pellet. Figure 23 presents a graph which shows the diameter and length of the resulting RHU as a function of thermal power.

The advantage of this approach is that it results in the smallest package for the fuel capsule. The disadvantage is that it requires completely new RHU tooling for all other components at every power level. 
SAME ASPECT RATIO

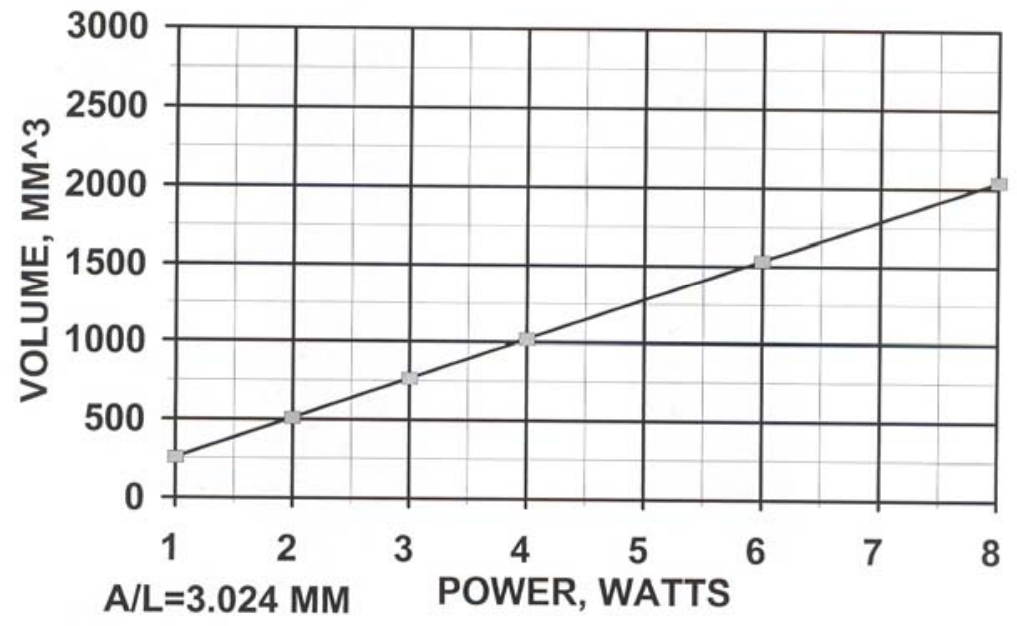

Figure 21. Pellet Volume as a Function of Power

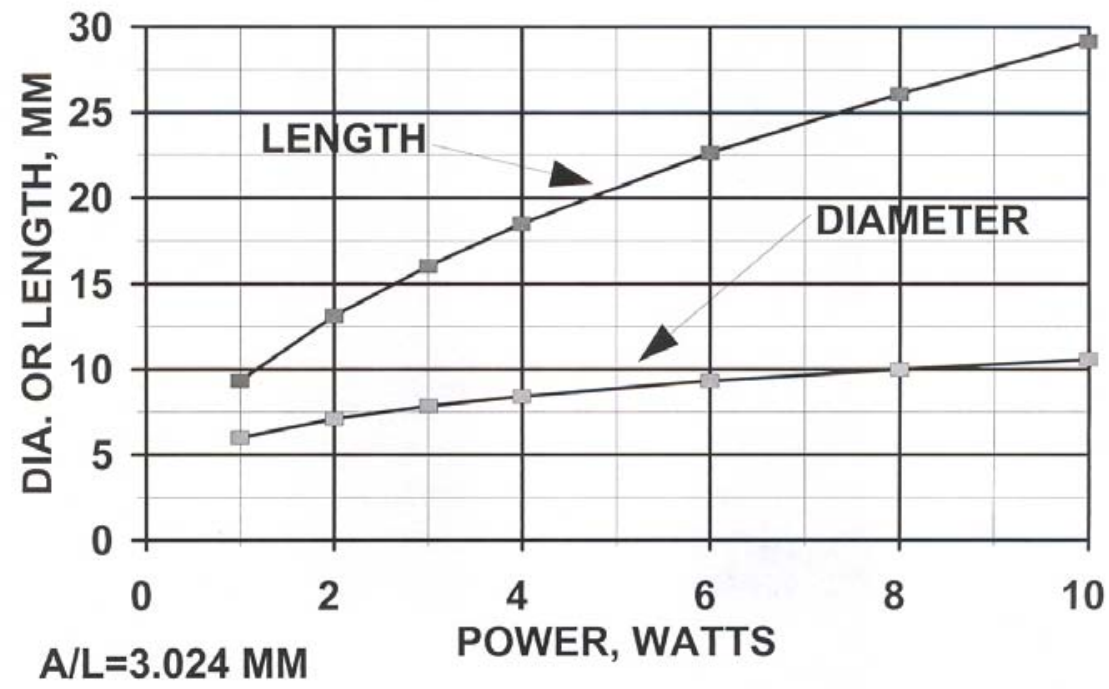

Figure 22. Pellet diameter and length as a function of power. Same A/L.

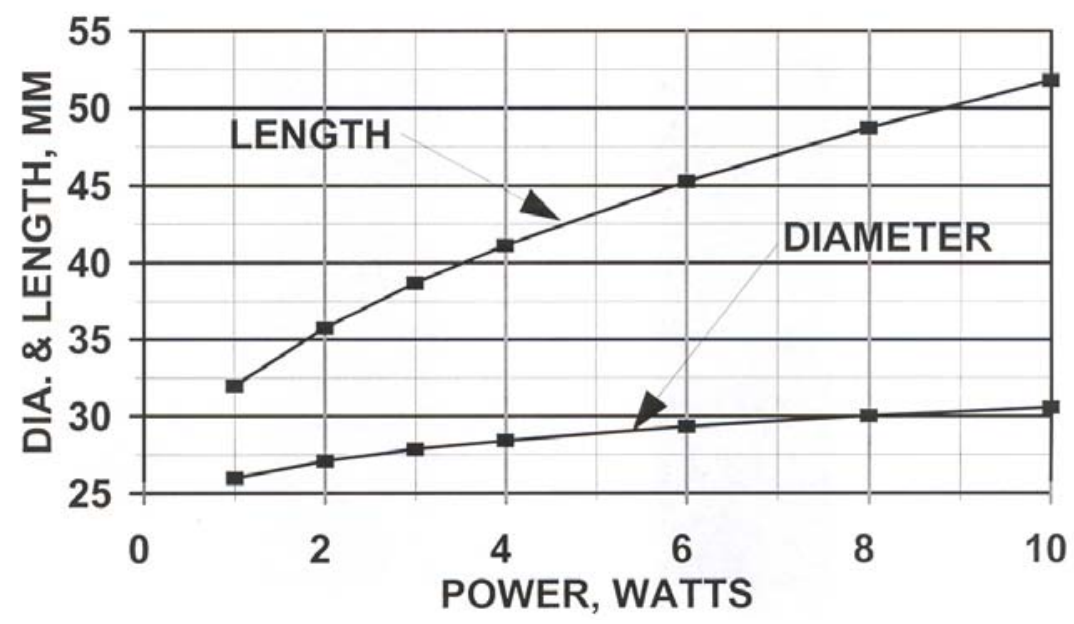

Figure 23. RHU diameter and length as a function of power, same $A / L$ 
Table 1 presents the theoretical outside diameter of various arrangements of RHU for between 1 Watt and 7 Watts using 1 Watt $\mathrm{PuO}_{2}$ sources. The arrangements are the same as shown by Wiley and Carpenter ${ }^{2}$, however in some cases the capsules have been stacked on top of each other as noted in the "comments" column.

Table 1. Dimensions for RHUs for Various Number of Fuel Pellets

\begin{tabular}{|c|c|c|l|}
\hline $\begin{array}{c}\text { Number of } \\
\text { Pellets }\end{array}$ & $\begin{array}{c}\text { Diameter } \\
(\mathbf{m m})\end{array}$ & $\begin{array}{c}\text { Height } \\
(\mathbf{m m})\end{array}$ & \multicolumn{1}{|c|}{ Comments } \\
\hline 1 & 26 & 32 & \\
\hline 2 & 26 & 44.6 & 2 high \\
\hline 2 & 37.48 & 32 & Side by side \\
\hline 3 & 38.97 & 32 & Side by side \\
\hline 4 & 37.48 & 44.6 & 2 high \\
\hline 4 & 41.47 & 32 & Side by side \\
\hline 5 & 44.24 & 32 & Side by side \\
\hline 6 & 38.97 & 44.6 & 2 high \\
\hline 6 & 47.13 & 32 & Side by side \\
\hline 7 & 47.13 & 32 & Side by side \\
\hline
\end{tabular}

When two $\mathrm{PuO}_{2}$ fuel pellets are stacked, it is assumed that they are each in individual clads. For the case using a single clad package for the fuel pellet one should subtract $3.2 \mathrm{~mm}$ from the stated length.

Table 2 presents a breakdown of the mass of the various components that go to make up both a 1 fuel capsule RHU ${ }^{(1)}$ as shown in Figure 1, and a 2 fuel capsule RHU, as shown in Figure 20. The total mass for the 1 capsule RHU is 40 grams and the total mass of the 2 capsule RHU is 57.7 grams. This compares to an 80 gram total if two separate RHU's are used, or a decrease of 22.3 grams or a $27.9 \%$ mass savings.

Table 2. Mass of 1 and 2 Fuel Capsule RHU

\begin{tabular}{|c|c|c|}
\hline \multicolumn{1}{|c|}{ Component } & $\begin{array}{c}\text { Mass for } \\
\text { 1 Fuel Capsule RHU } \\
\text { (grams) }\end{array}$ & $\begin{array}{c}\text { Mass for } \\
\text { 2 Fuel Capsule RHU } \\
\text { (grams) }\end{array}$ \\
\hline Aeroshell & 21.070 & 27.539 \\
\hline Aeroshell Plug & 2.543 & 2.543 \\
\hline Total Aeroshell Components & $\mathbf{2 3 . 6 1 3}$ & $\mathbf{3 0 . 0 8 2}$ \\
\hline Insulator top cap & 1.269 & 1.269 \\
\hline Insulator bottom cap & 1.263 & 1.263 \\
\hline Insulator outer tube & 3.166 & 4.857 \\
\hline Insulator middle tube & 1.486 & 2.432 \\
\hline Insulator inner tube & 0.624 & 1.068 \\
\hline Total Insulators & $\mathbf{7 . 8 0 8}$ & $\mathbf{1 0 . 8 8 9}$ \\
\hline Fuel pellet & 2.664 & 5.328 \\
\hline As-welded and vented & 5.702 & 11.40 \\
\hline Total fuel capsule & $\mathbf{8 . 3 6 6}$ & $\mathbf{1 6 . 7 3 2}$ \\
\hline & $\mathbf{3 9 . 7 8 7}$ & $\mathbf{5 7 . 7 0 3}$ \\
\hline
\end{tabular}




\section{Thermoelectric Module}

A picture of the thermoelectric module used in the latest $40 \mathrm{~mW}$ generator is shown in Figure 24. This module has two independent parallel circuits that are cross connected in 13 places. The original 40 $\mathrm{mW}$ module had only a single electric circuit.

The module used in the $80 \mathrm{~mW}$ generator would be he same, except that the length will be one half that of the $40 \mathrm{~mW}$ module. We have used variations of these $40 \mathrm{~mW}$ modules for several applications. For these applications the length of the modules is usually cut to as little as 0.070 inch long. One typical application was for the self-powered power supply prototype for wireless sensors built for the Navy ${ }^{(3)}$. This generator contained nine 0.070 inch long modules of the original design and worked on only a $5^{\circ} \mathrm{C}$ temperature difference. This is the temperature difference that exists between the hull of the ship, below the water line, and the ambient temperature in the engine room.

The current module is made of a solid composite of $\mathrm{N}$ and $\mathrm{P}$ type elements that measure 0.010 inch

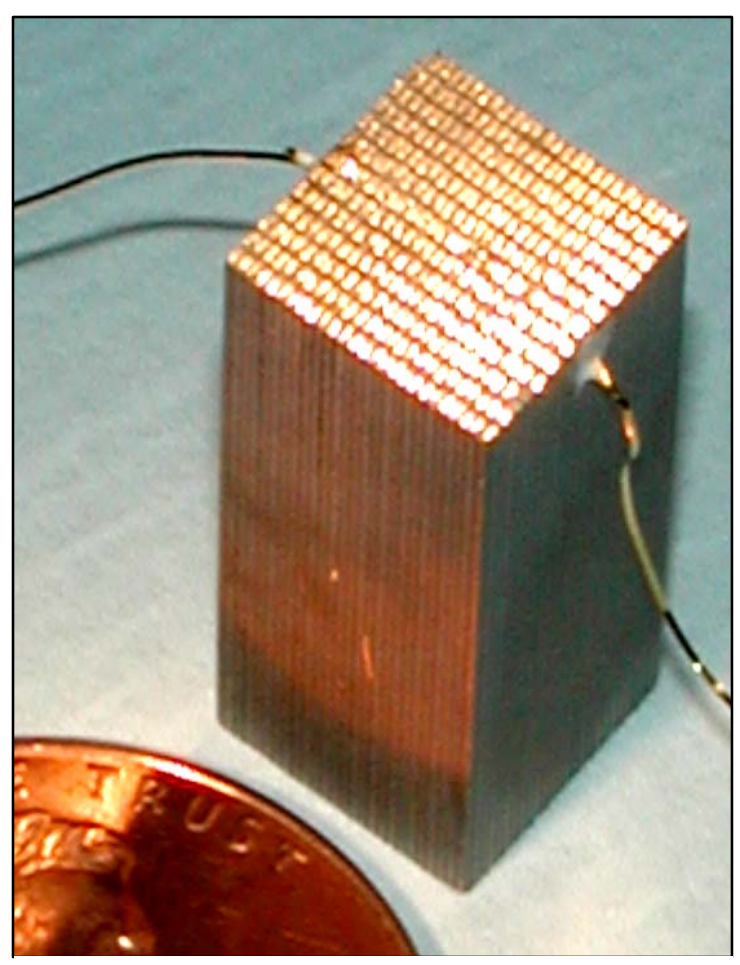

Figure 24. Parallel circuit thermopile consisting of 676 legs with 0.010 inch square legs. Brown disk in lower left corner is a penny. Module dimensions $0.29 \times 0.02 \times 0.9$ inch. square by 0.45 inch long for the $80 \mathrm{~mW}$ RTG. The elements are arranged in a $26 \times 26$ array. When completed, the module measures 0.29 inch square by 0.45 inch long. The elements are arranged in sections of $13 \times 26$ elements. The elements are connected as shown in Figure 25 on the cold side to provide the two redundant circuits with 13 cross connectors.
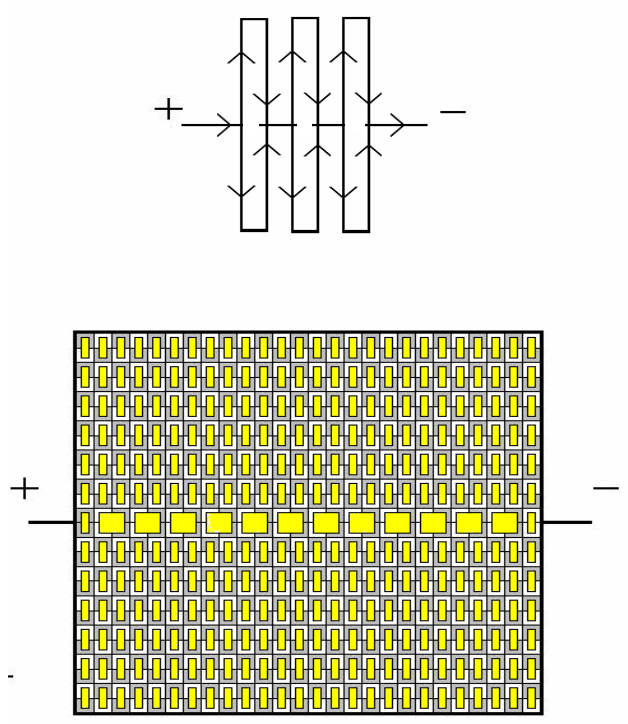

Figure 25. Thermopile circuit cluster design. Arrows indicate direction of electron flow. 


\section{Future Testing of $\mathrm{mW}$ Generators}

Under another DOE contract a new group of test stations were constructed so that $\mathrm{mW}$ modules and generators can be life tested in high vacuum or Xenon gas (Figures 26 and 27).

The new test stations run at a pressure of $\sim 1 \mu$ torr and the module cold side can be controlled down to $-10^{\circ} \mathrm{C}$ using a Peltier module on two stations (Fig. 28) and $-160^{\circ} \mathrm{C}$ on the cryogenic station using liquid $\mathrm{N}_{2}$ (Fig. 29). The use of heating tape and getters may allow for a lower vacuum to be obtained. The use of multi-staged Peltier coolers may further lower the module cold side temperature below $-10^{\circ} \mathrm{C}$.

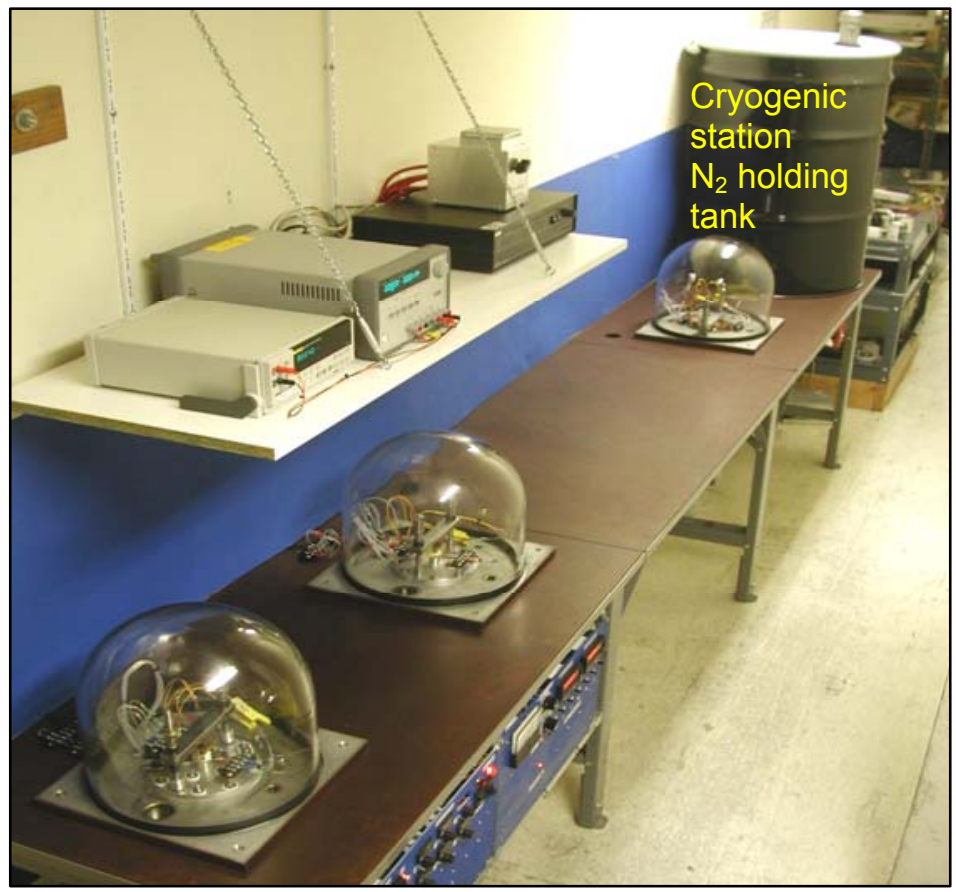

Figure 26. The new test stations run at a pressure of $\sim 1 \mu$ torr and the module cold side temperature can be controlled down to $-10^{\circ} \mathrm{C}$ on two stations and $-160^{\circ} \mathrm{C}$ on the cryogenic station.

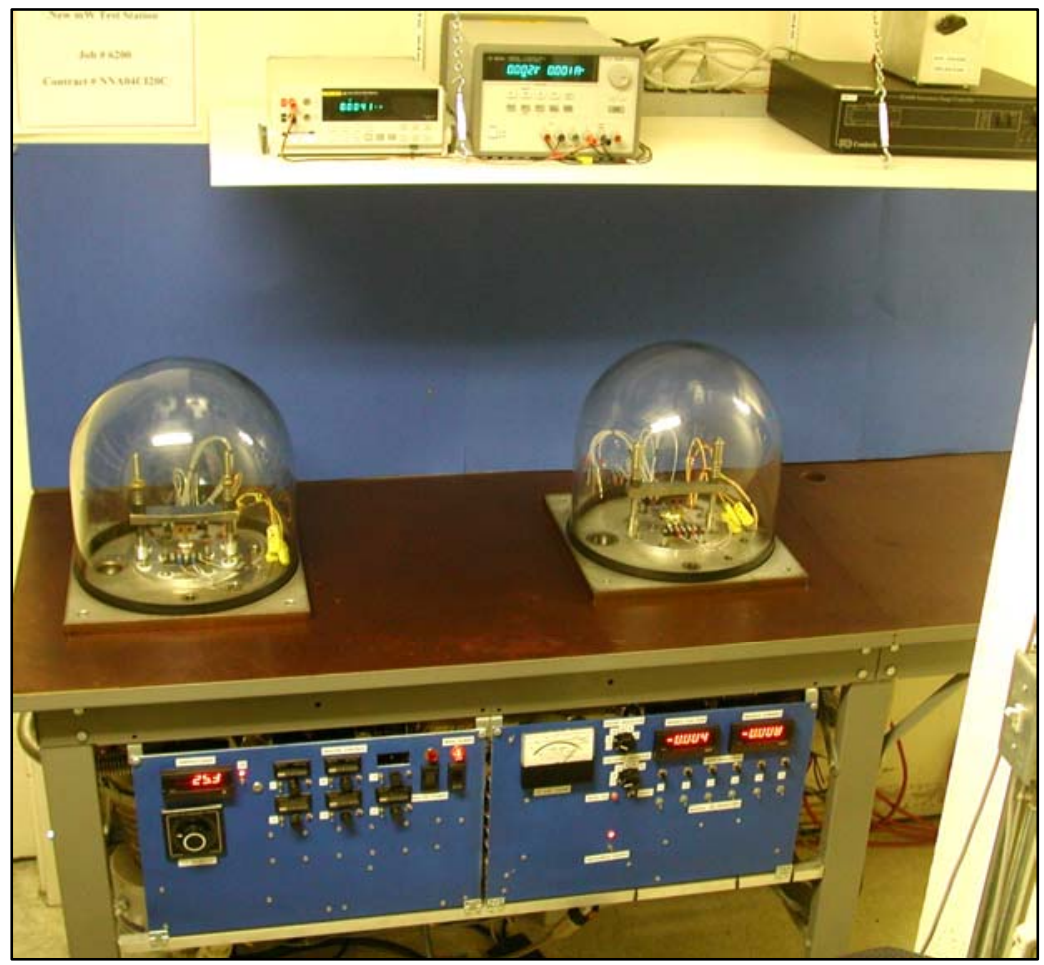

Figure 27. Front view of new test stations that run at a pressure of $\sim 1 \mu$ torr and the module cold side temperature can be controlled down to $-10^{\circ} \mathrm{C}$ on two stations and $-160^{\circ} \mathrm{C}$ on the cryogenic station. 


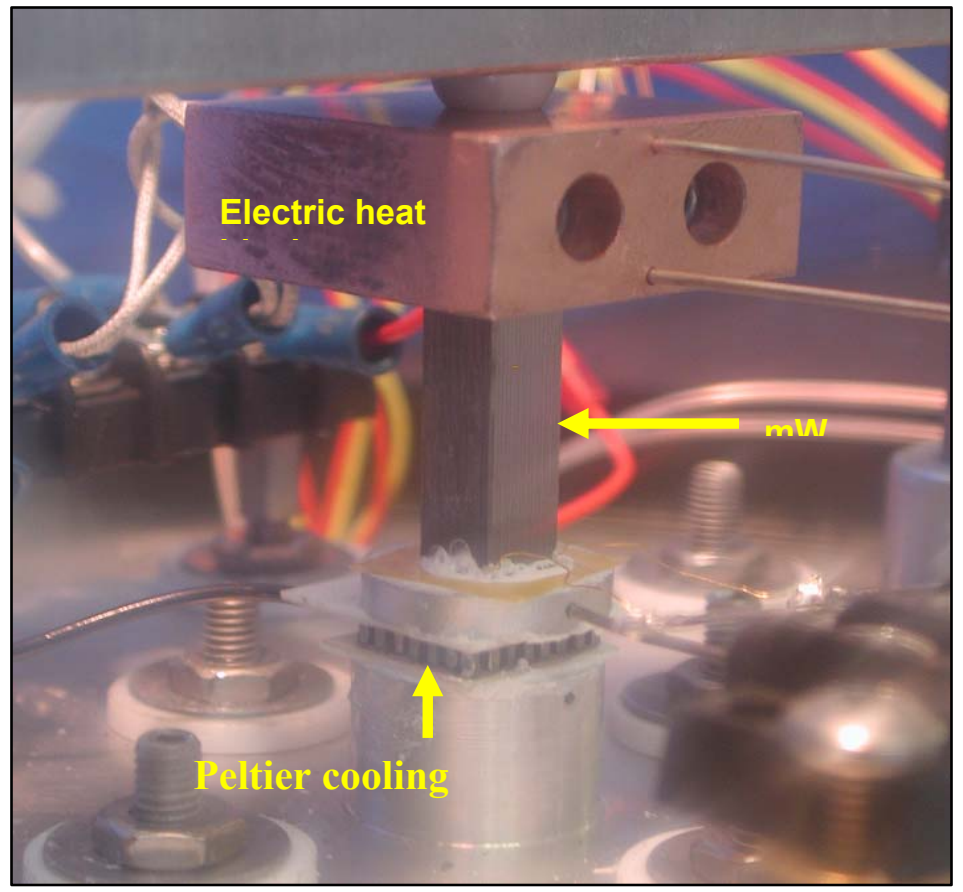

Figure 28. Close-up view of module in the completed new module test station.

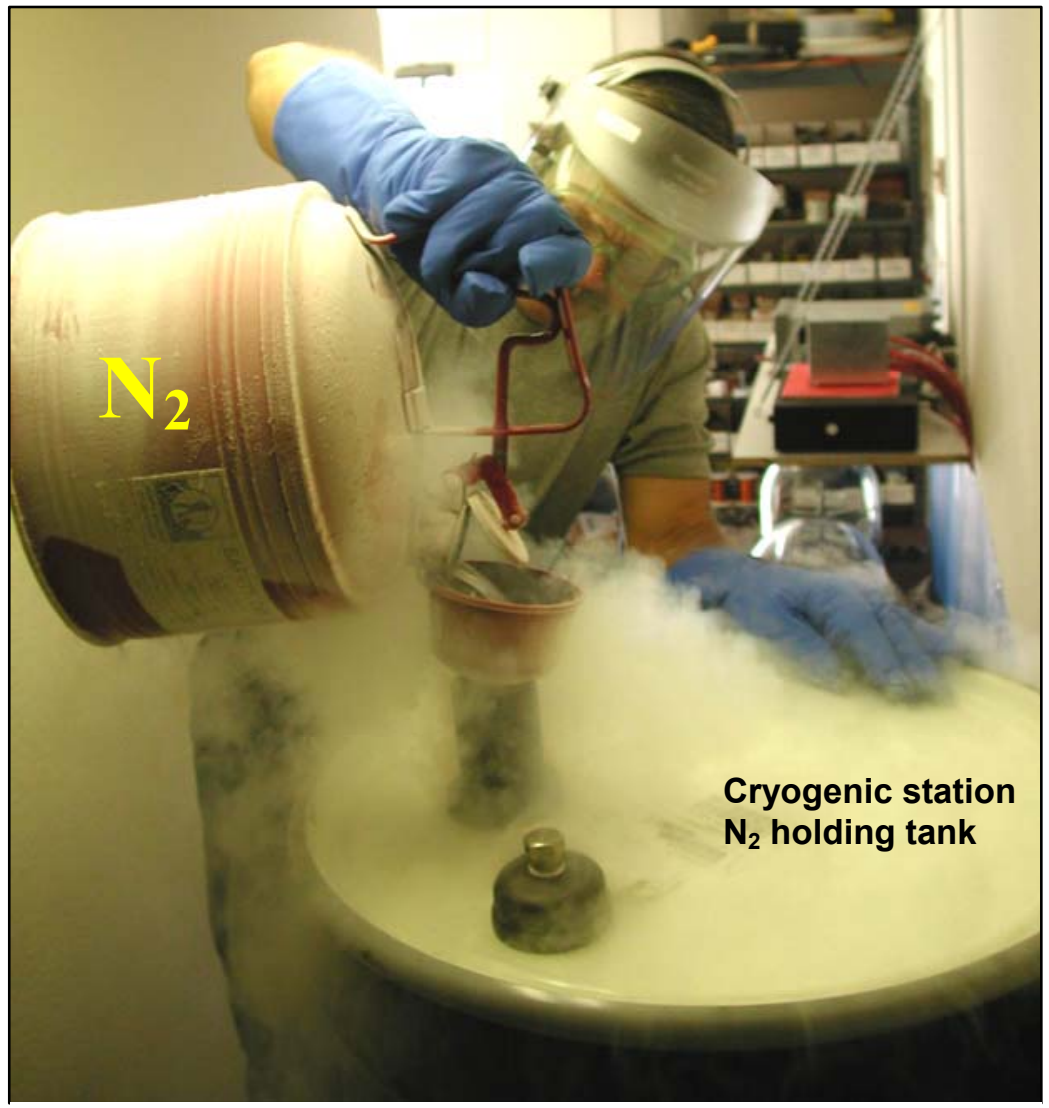

Figure 29. Close-up of module in the completed new module test station 
A LabView program was developed to impose a wide range of temperatures on the module's cold side during life testing. Specifically this program has the capability of: temperature stabilization, mild and well controlled thermal cycling, and rapid and maximized thermal cycling. The front panel of this program is shown in Figure 30 and the data displayed on the control panel demonstrates all three of these temperature control capabilities. Each of these functions is described in more detailed on the next page.

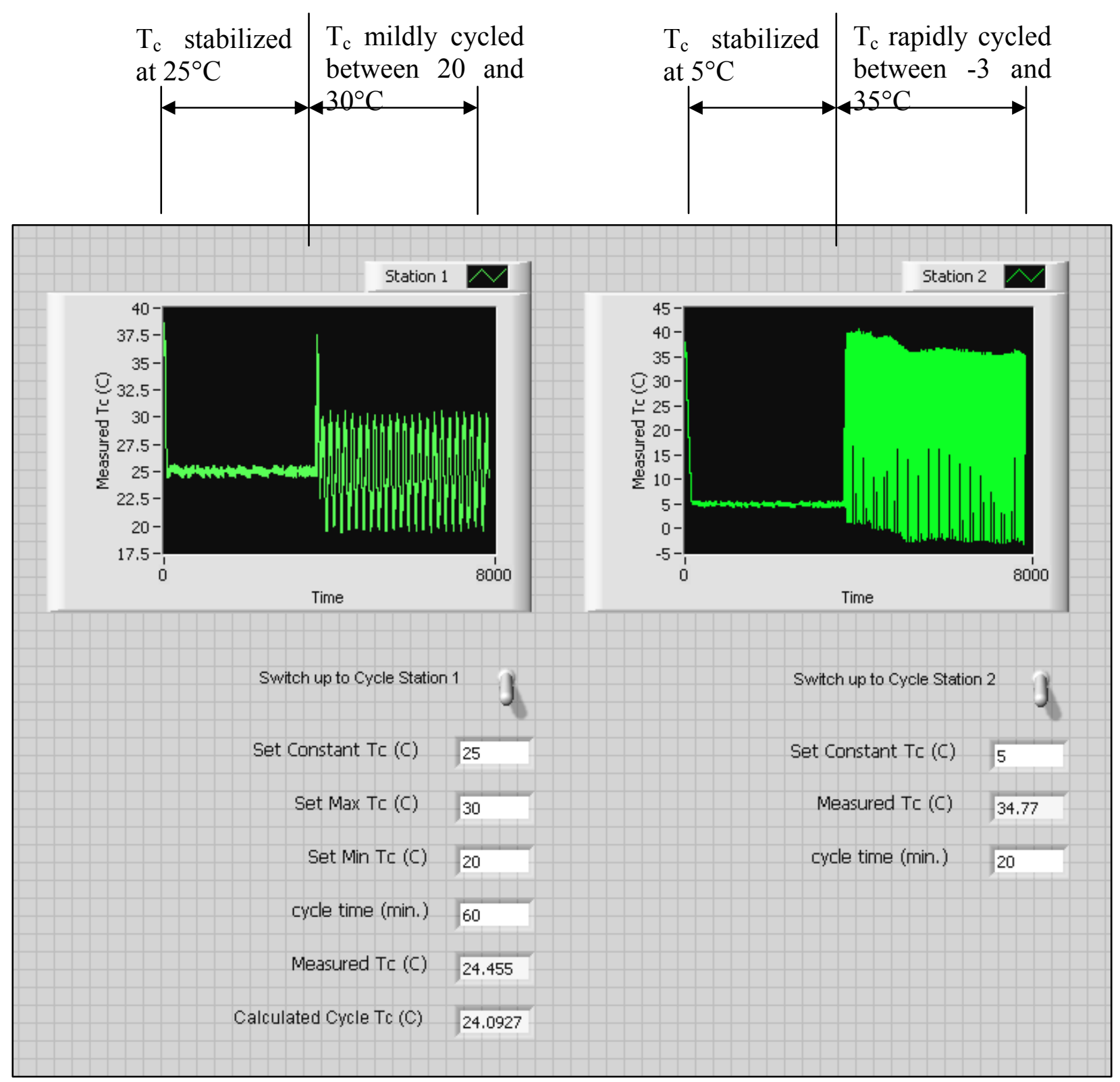

Figure 30. Front panel of LabView program developed to impose a wide range of temperatures on the module's cold side during life testing. Specifically this program has the capability of: temperature stabilization, mild and well controlled thermal cycling, and rapid and maximized thermal cycling. 


\section{Temperature Stabilization}

The purpose of controlling the $\mathrm{mW}$ module cold side temperature is to stabilize the modules power output so that degradation in power can be accurately measured (if degradation exists). Currently the module $\mathrm{T}_{\mathrm{c}}$ can be controlled between $-10^{\circ} \mathrm{C}$ and $35^{\circ} \mathrm{C}$ with an accuracy of $\pm 1 / 2^{\circ} \mathrm{C}$ as indicated by the data collected over an eight hour period and displayed in Figure 31. Note in Figure $31 \mathrm{~A}$ that $24.5<\mathrm{T}_{\mathrm{c}}<25.5^{\circ} \mathrm{C}$ and in Figure $31 \mathrm{~B}$ that $4.4<\mathrm{T}_{\mathrm{c}}<5.5^{\circ} \mathrm{C}$. The accuracy of the programs temperature stabilization can be greatly improved using any one of a variety of control theory techniques (fine tuning the cycle time and voltage output).

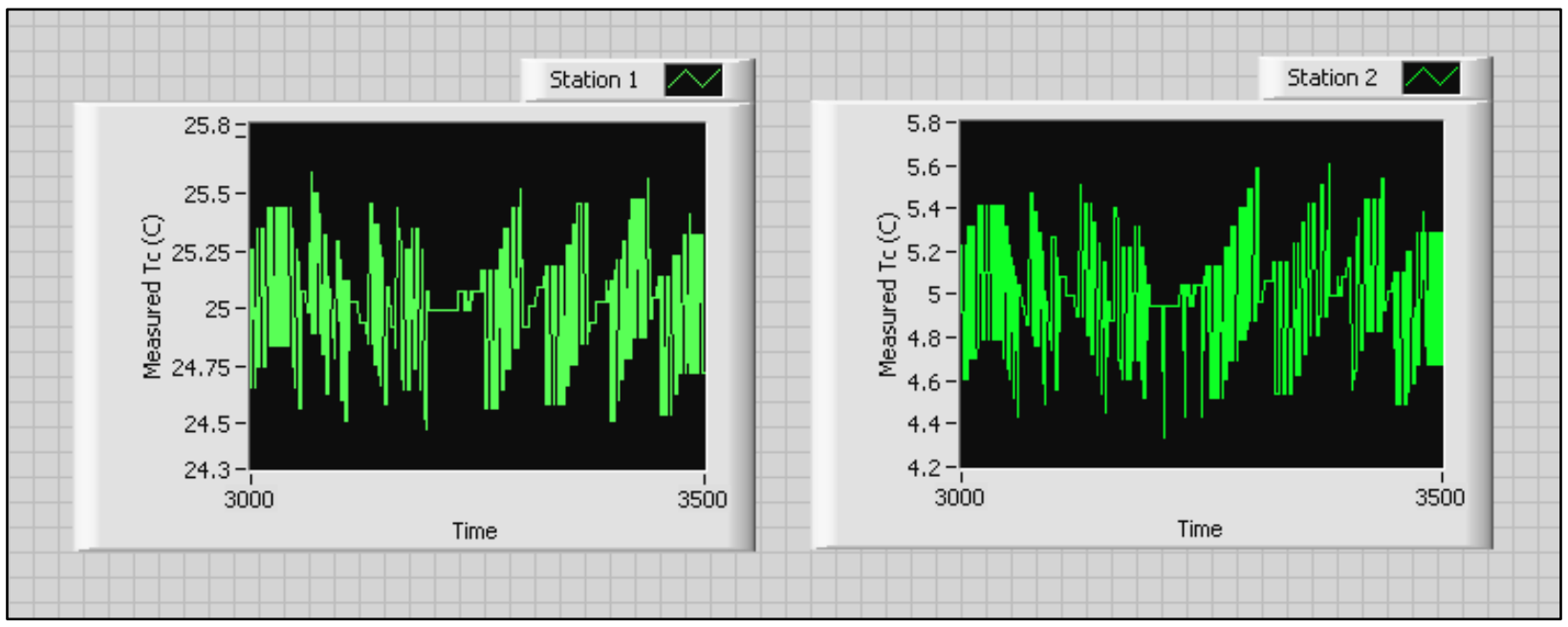

Figure 31 . The module $\mathrm{T}_{\mathrm{c}}$ can be controlled between $-10^{\circ} \mathrm{C}$ and $35^{\circ} \mathrm{C}$ with an accuracy of $\pm 1 / 2^{\circ} \mathrm{C}$ as indicated by the data collected over an eight hour period and displayed here.

\section{Thermal Cycling}

The LabView program developed is capable of mild and well controlled thermal cycling. This program allows the user to select the max and min temperatures, and cycle time. The program cycles the module cold side temperature between these max and min temperature values at a rate that results in a sinusoidal temperature vs. time shape. In the case of Figure $31 \mathrm{a} \mathrm{T}_{\max }=30^{\circ} \mathrm{C}, \mathrm{T}_{\min }$ $=20^{\circ} \mathrm{C}$ and the cycle time is 200 minutes as indicated by the data collected over an eight hour period and displayed in Figure 31a.

The LabView program developed is also capable of rapid and maximized thermal cycling. This program only allows the cycle time. The program cycles the module cold side temperature to the highest and lowest values achievable by the hardware given the ambient temperature of that particular day. In the case of Figure $32 \mathrm{~b}$ the cycle time is 50 minutes and the highest and lowest achievable cold side temperature is $35^{\circ} \mathrm{C}$ and $-2^{\circ} \mathrm{C}$, respectively, as indicated by the data collected over an eight hour period and displayed in Figure 32b. In another module $T_{c}$ reduction test $\mathrm{T}_{\mathrm{c}}$ was reduced as far down as $-15^{\circ} \mathrm{C}$ as shown in Figure 33 . 


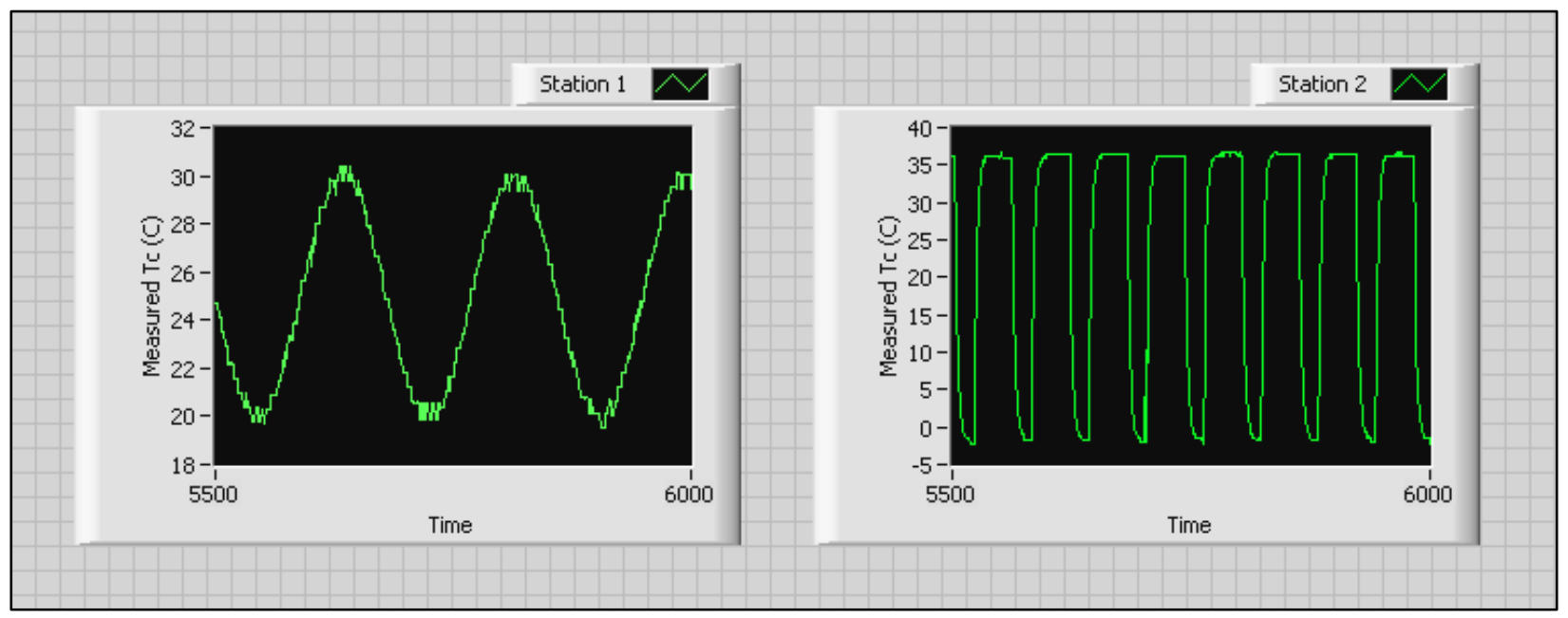

Figure 32. A) LabView program for mild and well controlled thermal cycling. This program allows the user to select the max and min temperatures, and cycle time. The program cycles the module cold side temperature between these max and min temperature values at a rate that results in a sinusoidal temperature vs. time shape. In the case of figure $12 \mathrm{a} \mathrm{T}_{\max }=30^{\circ} \mathrm{C}, \mathrm{T}_{\min }=20^{\circ} \mathrm{C}$ and the cycle time is 200 minutes. B) LabView program for rapid and maximized thermal cycling. The program cycles the module cold side temperature to the highest and lowest values achievable by the hardware given the ambient temperature of that particular day. In this case the cycle time is 50 minutes and the highest and lowest achievable cold side temperature is $35^{\circ} \mathrm{C}$ and $-2^{\circ} \mathrm{C}$, respectively.

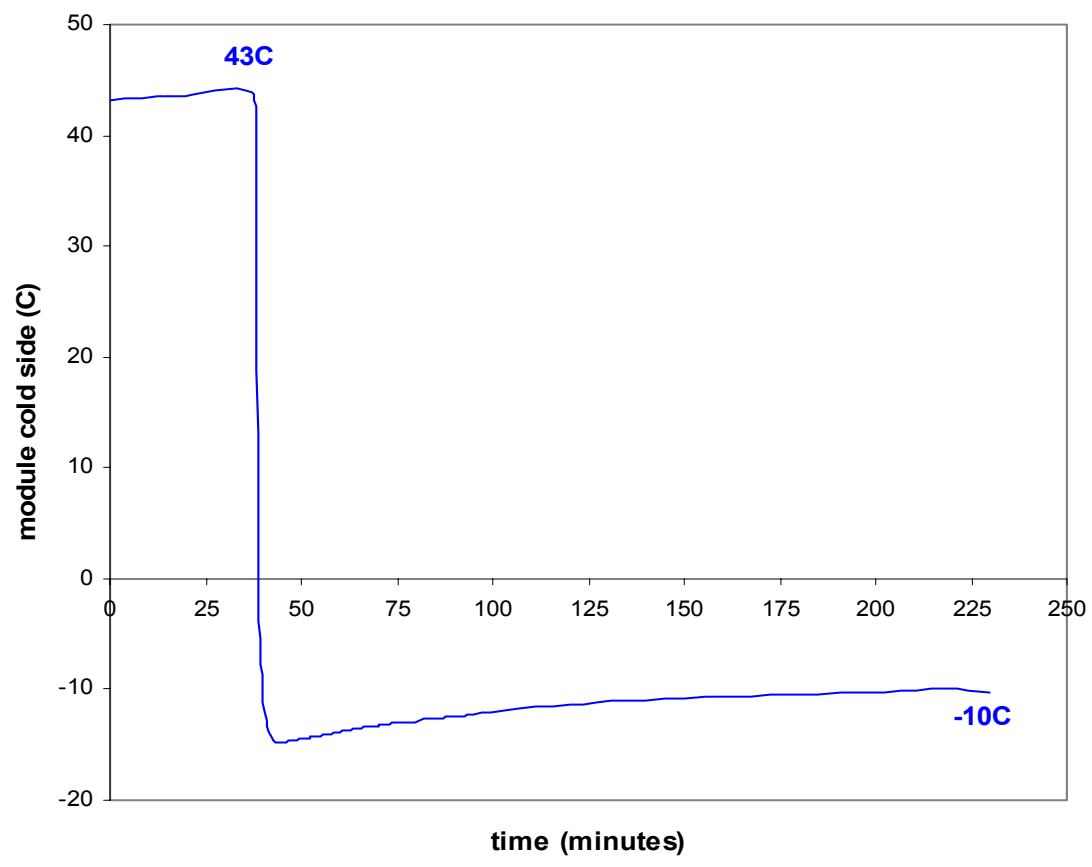

Figure 33. In this module $T_{c}$ reduction test $T_{c}$ was reduced as far down as $-15^{\circ} \mathrm{C}$. 


\section{Fuel Capsule}

The original design for the $40 \mathrm{~mW}$ RTG shown in Figure 1 had the heat source and capsule holder sitting on the top of the thermopile. The heat source and capsule holder were held in place by four wires which provide a load against the thermopile. Any sharp loads in directions other than in line with the centerline and in the direction of the cold shoe are taken by the tie wires which prevent movement of the heat source capsule holder.

The original design, shown in Figure 1 worked well in a low shock environment. It was tested by NASA Ames and failure did not occur until the lateral shock was between $700 \mathrm{~g}$ 's and 1000 g's. The exact failure point was not well defined.

What happens during a high lateral load is that the fuel capsule holder tends to rock about one edge of the thermopile. The capsule holder then lifts off from one side and the tension in the spring loaded wires tend to snap the capsule holder back into its original position. When the shock is terminated, failure usually occurs either by crushing some of the thermoelectric material at the point where the rocking takes place, or by causing the electric contacts welded to the end surface of the thermoelements to fail as the capsule holder returns to its original position. Contact failure can create one or more open circuits which can result in module failure.

The 700 to $1000 \mathrm{~g}$ acceleration should work for most cases where the $40 \mathrm{~mW}$ RTG would be used. However, a number of missions may require higher g loadings of the order of 3000 to 5000 g's.

Hi-Z looked at several design options. Some of these had built-in devices to limit movement of the heat source capsule holder to prevent lift off as the result of lateral high g loads.

The design we finally selected took an entirely different design approach to solve the problem. In this approach the heat source capsule holder is suspended by four wires located in pairs, two at the top and two at the bottom of the capsule holder displaced $90^{\circ}$ from the first pair.

The thermopile is held in place by a separate set of four wires which run from the fuel capsule holder to the cold shoe. The cold shoe is thermally insulated to minimize heat flow from the fuel capsule holder, through the wire, and to the cold side of the thermopile.

The cold shoe is free to move in a semi planar motion. Heat is transferred from the cold shoe to the RTG case through a graphite felt pad which allows the free movement of the cold shoe.

The following is a commentary on how to assemble the fuel capsule (RHU) and assemble the high $\mathrm{G}$ capable milliwatt generator using the $2 \mathrm{~W}$ fuel capsule RHU. A step-by-step description is given here. This is one suggested assembly procedure that appears feasible. Changes in the order of assembly will likely occur as we get further into the detail design of the generator.

Some of the details of the RHU assembly are left out, however, they are the same for this RHU as for the previous one. The only difference in fuel capsules is that this $2 \mathrm{~W}$ capsule contains two $\mathrm{PuO}_{2}$ pellets instead of one. 


\section{$\underline{\text { RHU Assembly }}$}

The first four drawings (Figs. 34 through 37) depict the components of the RHU. The two 1W fuel pellets used are shown in green. The last drawing of this first series is the completed $2 \mathrm{~W}$ RHU which will be used to fuel the generator assembly. This RHU assembly will require the redesign on production of all the interior graphite pieces and the use of two $1 \mathrm{~W} \mathrm{PuO}_{2}$ pellets of the existing design.

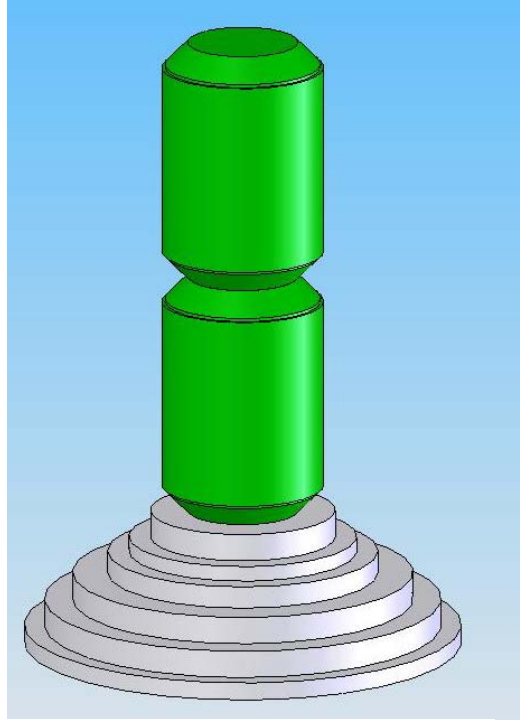

Figure 35. Fuel pellets, insulator and base assembled

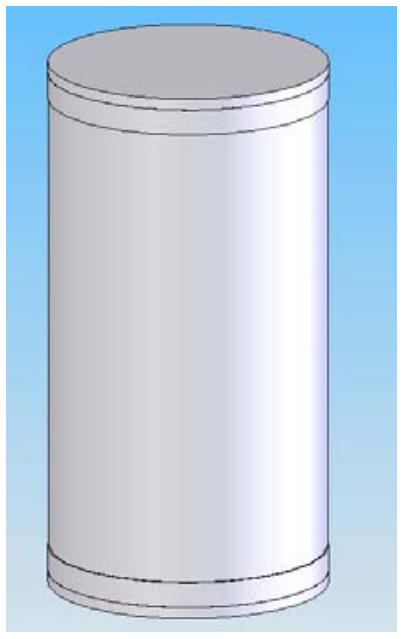

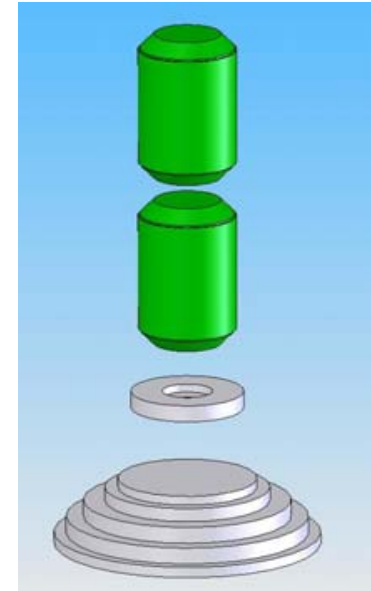

Figure 34. Fuel pellets, Insulator and base of $2 \mathrm{~W}$ heat source
Figure 36. Fuel pellets and radial shields
Figure 37.

Completed 2 fuel pellet RHU

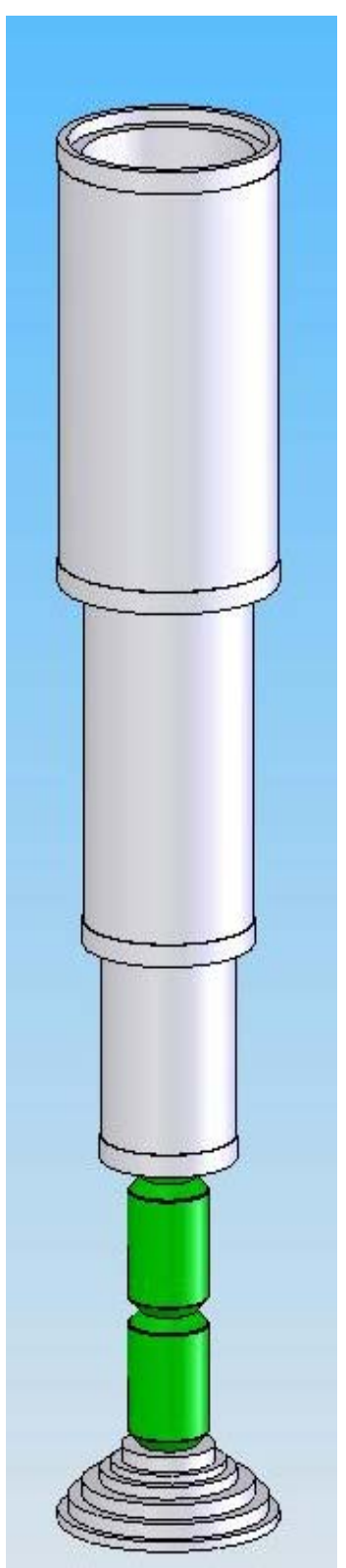




\section{Generator Assembly}

Figure 38 shows the upper and lower support rings along with the four support wires. These items will be made from titanium alloy.

The support rings are attached to the fuel capsule holder by passing the notched cutouts on the support rings past the matching spline on the fuel capsule. The upper ring slips on first, followed by the lower ring. Once in place, the rings are rotated about the vertical centerline so that the splines on the fuel capsule fit into the pockets in the support rings to lock the ring in place as shown in Figure 39.

Figure 40 shows the thermopile attached to the fuel capsule holder. A piece of 0.001 inch thick Kapton (not shown) will be placed between the thermopile and the fuel capsule holder to provide electric insulation.

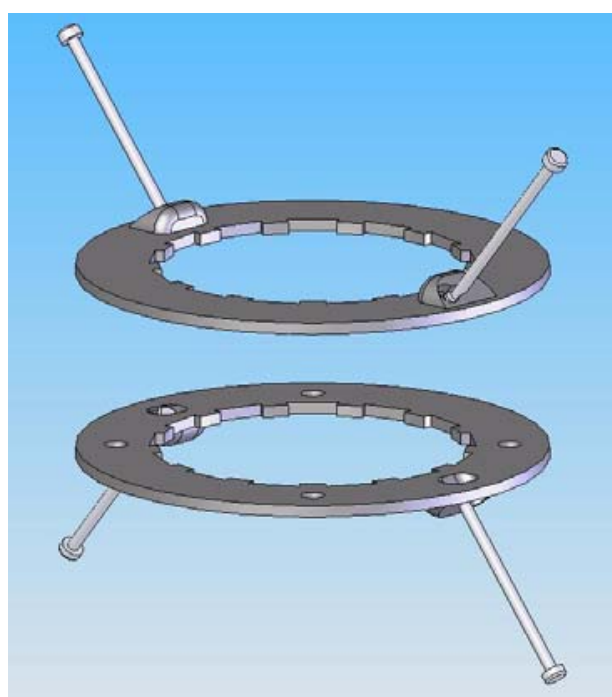

Figure 38. Support rings and wires

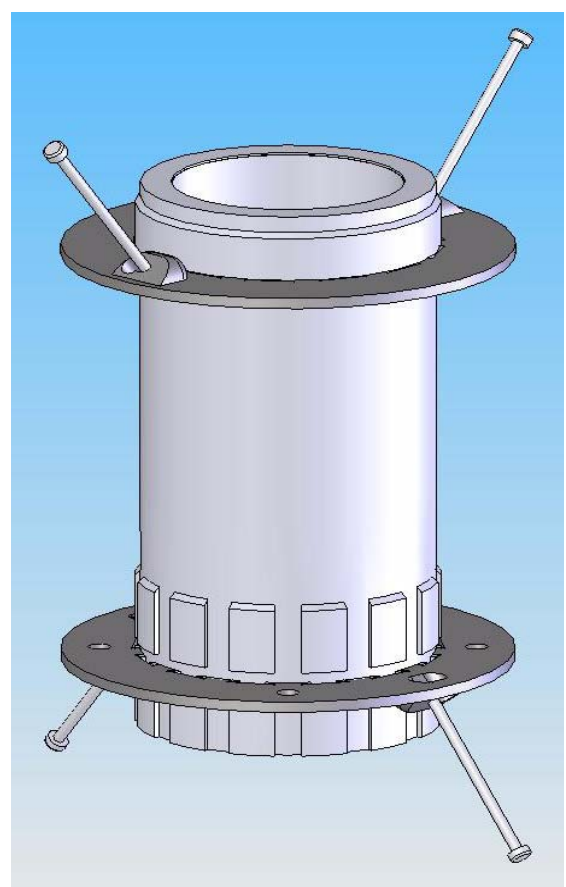

Figure 39. Support rings in place on fuel capsule holder

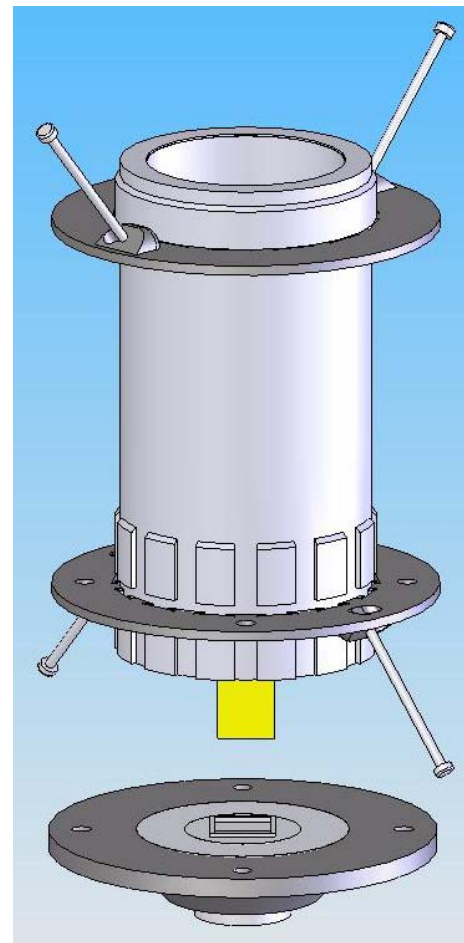

Figure 40. $80 \mathrm{MW}$ module in place and lower module support 
Figure 41 shows the three pieces of the lower module support. The central piece is aluminum, the outer piece is titanium and the piece in between is Vespel plastic. This design will help thermally isolate the heat leaked down the support wire from the cold junction of the TE module.

Figure 42 shows the assembly of the pieces of the module support in place.

Figure 43 depicts the assembly of the module support wires. These wires are made of titanium alloy to minimize the heat leakage.

Figure 44 depicts the assembly of the Belleville washers, nuts and washer alignment tubes. These pieces are made of stainless steel alloy. The nuts will be tightened to provide 200 psi of compression on the thermopile.

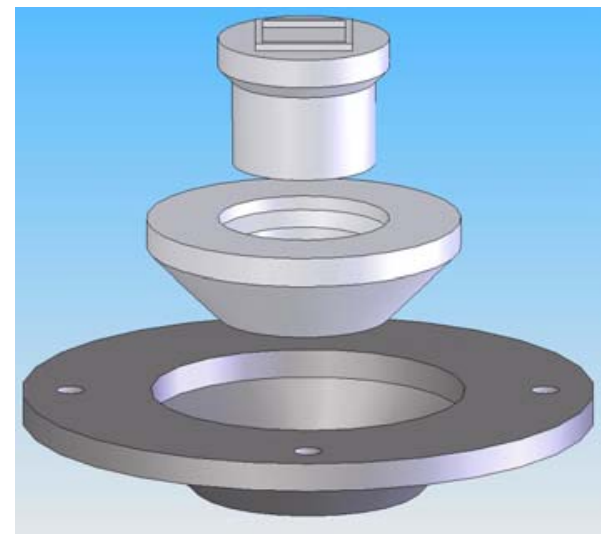

Figure 419. Lower module sunnort

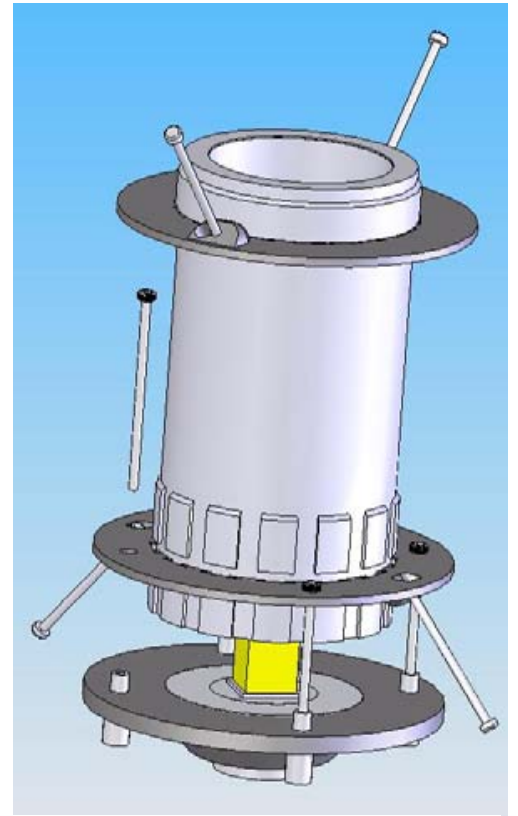

Figure 43. Assembly of module support wires

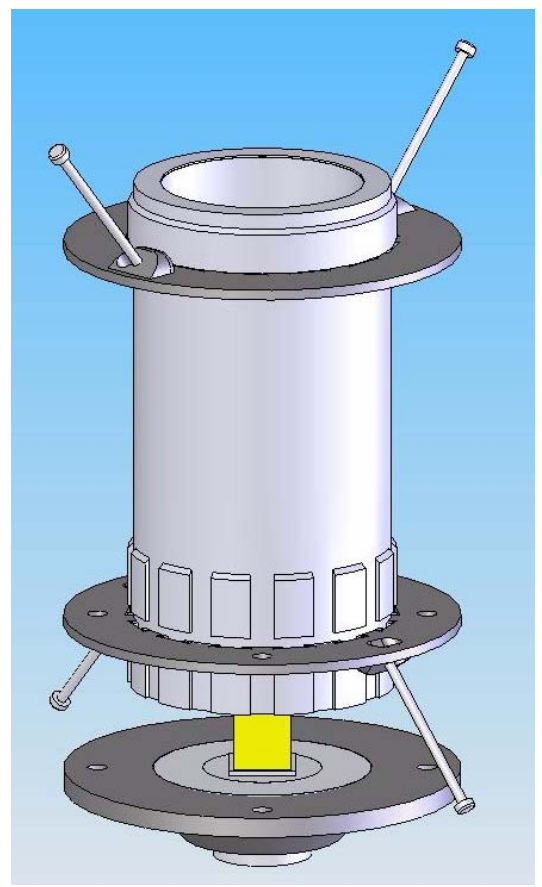

Figure 42. Assembly of inner pieces of generator

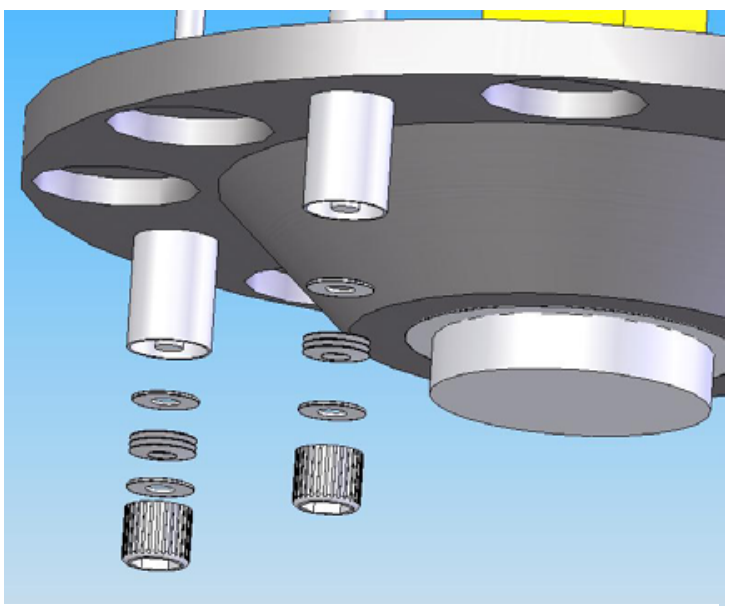

Figure 44. Assembly of Belleville washers and nuts 
Figure 45 shows the entire inner subassembly.

Figure 46 shows the inner subassembly inserted into the lower half of the support tube (this tube is made of titanium). The free ends of the lower generator support wires are fed through the two catch holes in the lower half of the support tube. The fuel capsule holder assembly and module are lifted until the wires are engaged in the catch holes. Note the four holes in the lower support tube. These holes will be used later to pull the two halves of the support tube apart and to provide visual access to the bottom of the heat sink.

Figure 47 shows the inner assembly in place with a tool to hold the generator in place vertically.

Figure 48 shows the upper half of the support tube (titanium alloy) being lowered over the inner assembly. The upper support

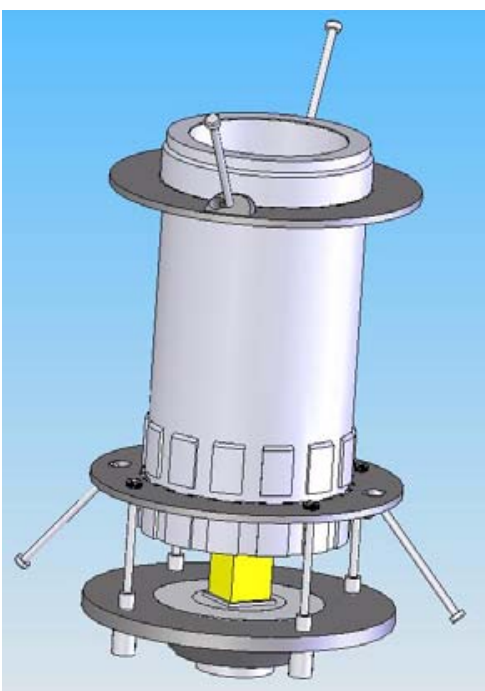

Figure 45. Inner assembly complete generator wires are fed through the catch holes in the upper support tube and moved sideways to lock them in place. Note the large holes in the upper support that are used to pull the two halves of the support tube apart (see below).

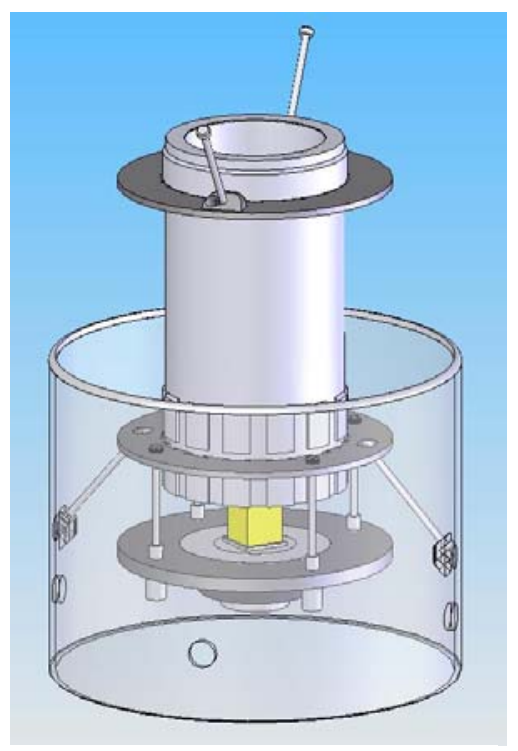

Figure 46. Inner assembly attached to lower tube

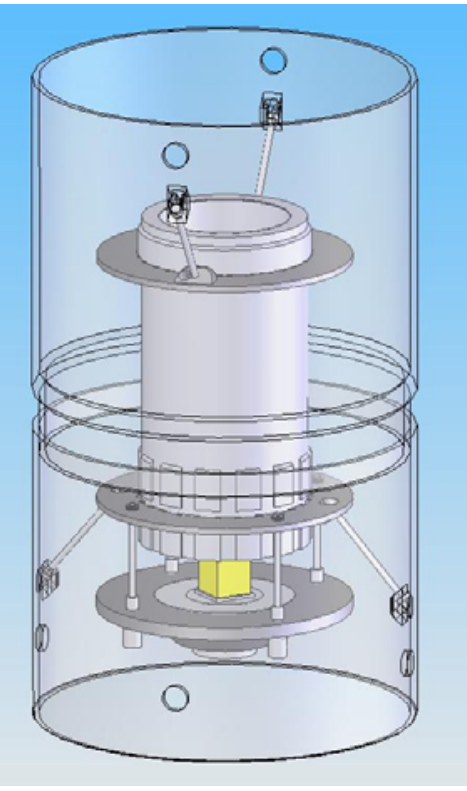

Figure 48. Upper support tube in place

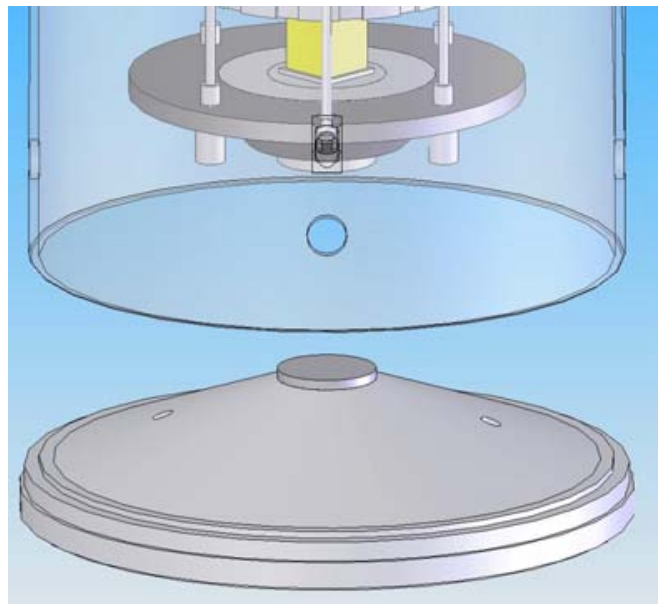

Figure 47. Tools in place to hold assembly in place 
Figure 49 shows that special tooling, not designed as yet, is used to engage the holes in the two halves of the support tube to pull the two halves apart and provide equal tension of about 40 pounds in each of the four generator support wires. The two halves of the inner support tube are welded together to maintain the tension in the support wires (see arrow).

Figure 50 shows the installation of the lower thermal insulation and the radial thermal insulation.

Figure 51 shows the bottom heat sink plug (aluminum) in place. Thermal contact between the bottom of the thermopile support and the heat sink is made by a graphite felt pad. It can be inspected through the lower portion of the support tube to insure that there is positive contact between the two components. The electrical connection between the module and the feedthroughs is made at this time

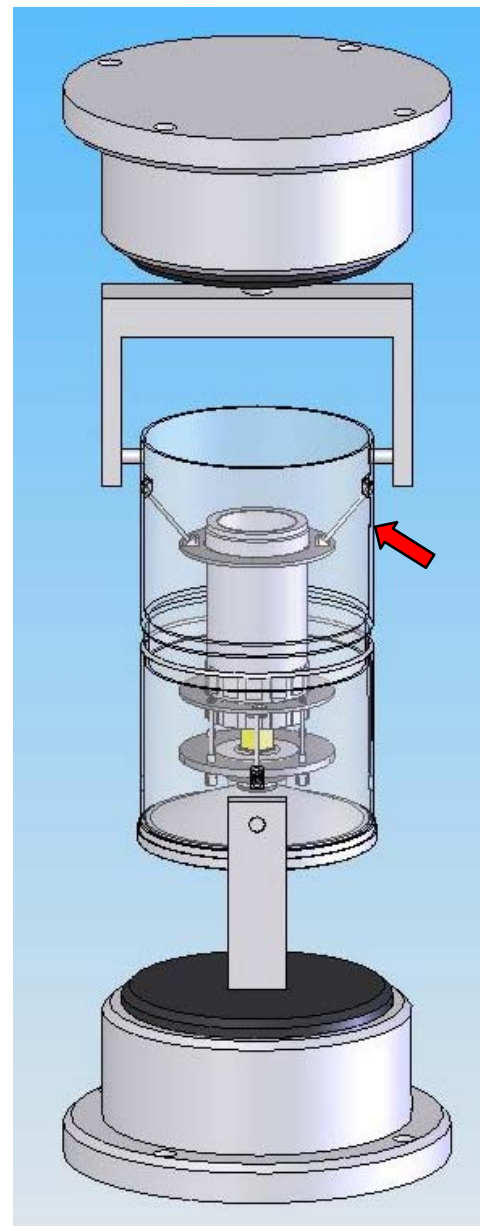

Figure 50. Two halves of support tube being pulled apart
Figure 49. Lower thermal shields in place

Figure 51. Bottom heat sink plug in place. Seen are the graphite pad and electric feed through
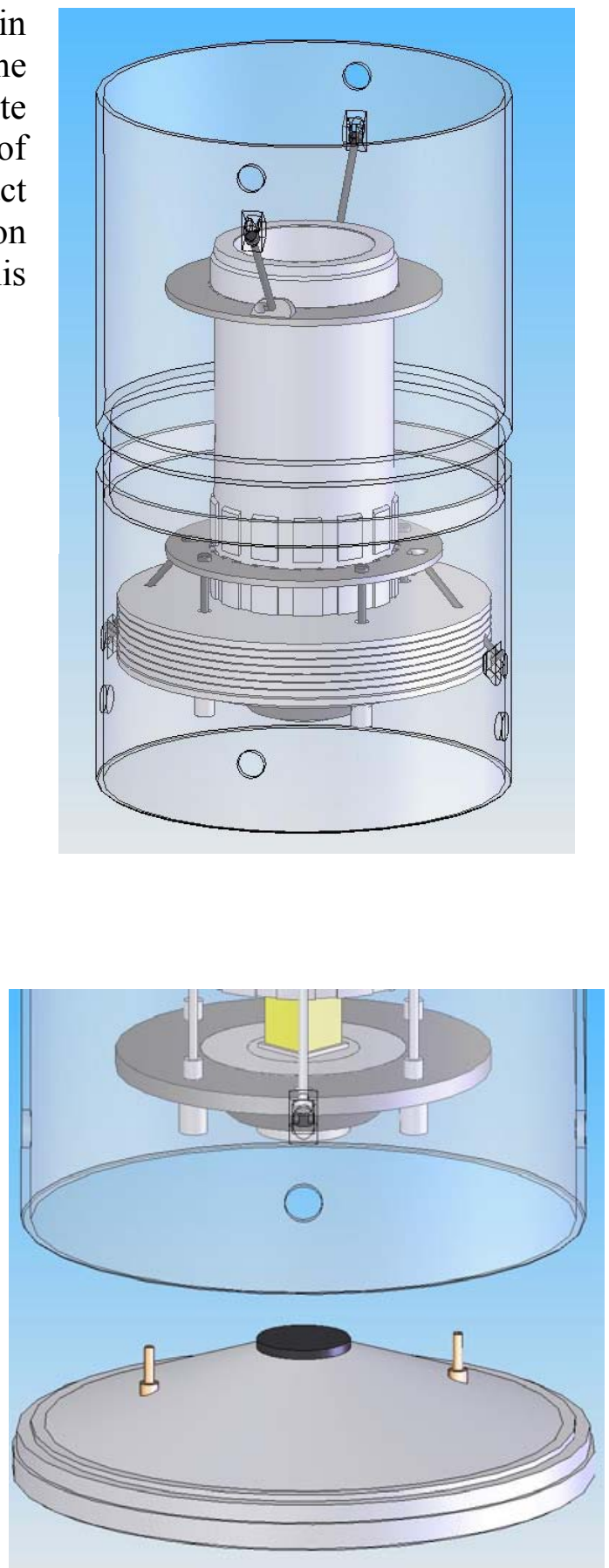
Figure 52 shows the radial thermal shields in place.

Figure 53 shows the electric connections between the module and feed through. Soldering of the connections is made through the holes in the side of the lower support tube.

Figure 54 shows the joining of the pressure shell (aluminum) and the inner assembly. The joint between the bottom plate (aluminum) and the pressure shell will be EB welded (arrow) and leak checked. Thermal shields are not shown for clarity.

Figure 55 shows the two watt RHU, see Figures 34-37, being lowered into the assembly. This and the remaining tasks will be carried out in a glove box at INEL. The pressure shell is not shown for clarity

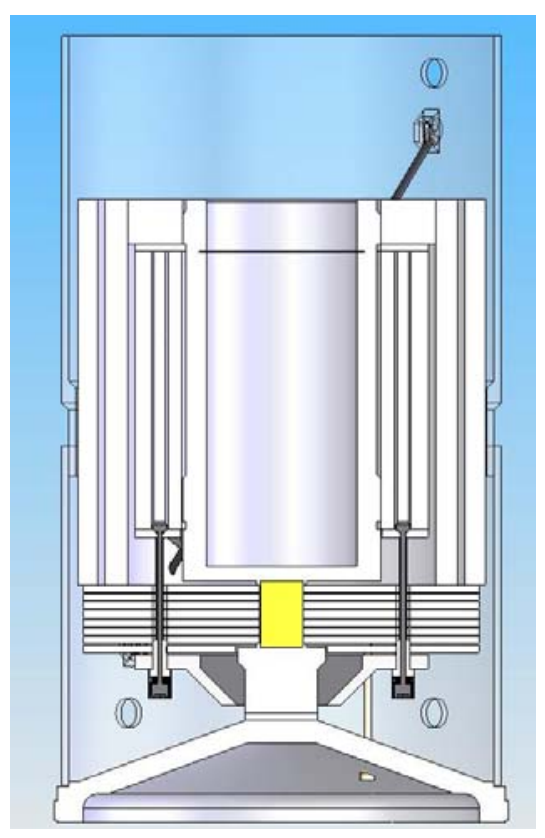

Figure 52. Radial thermal shield in place

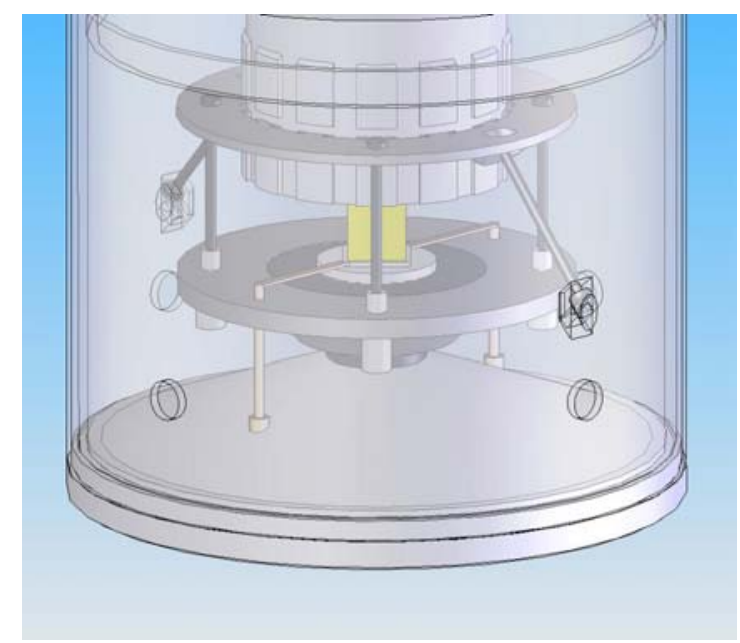

Figure 54. Pressure shell and inner assembly

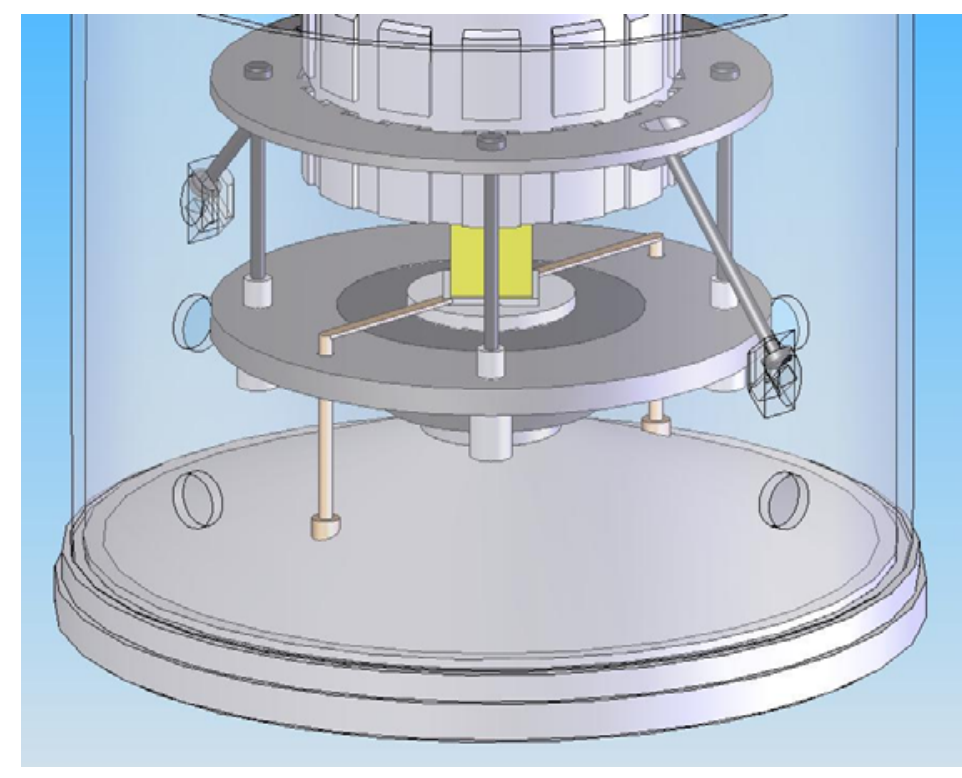

Figure 53. Electrical connection through side holes

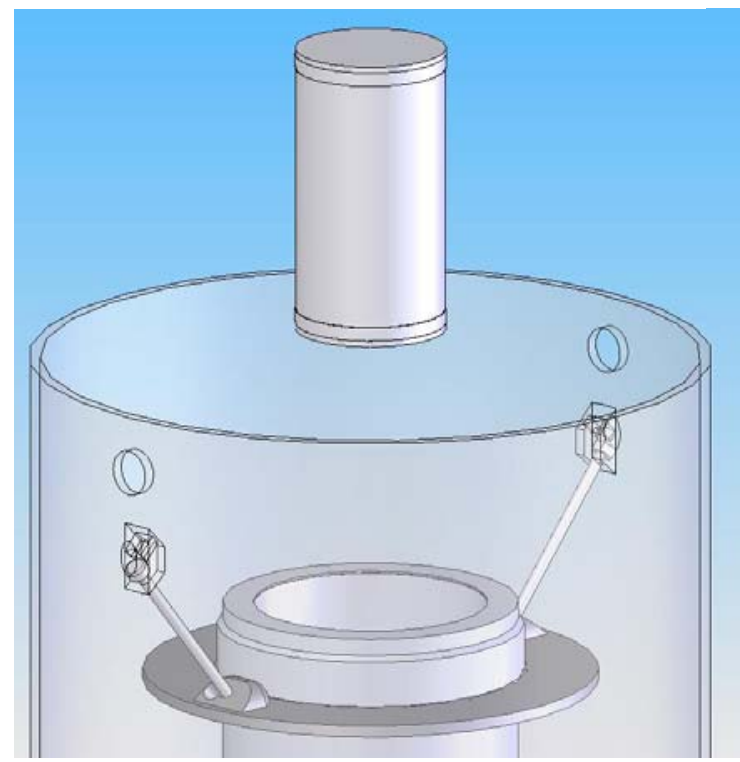

Figure 55. 2W RHU being loaded into fuel capsule holder 
Figure 564 shows the fuel capsule hold-down device (aluminum and steel springs) being put in place following the inserting of the RHU. The screw (steel) in the capsule hold-down device will be adjusted to provide a compressive force between the RHU and the bottom of the fuel capsule holder to insure good heat transfer between the RHU and the bottom of the fuel capsule holder.

Figure 57 shows the fuel capsule cap (aluminum) complete with the getter being installed in the fuel capsule holder. The cap will be EB welded in place and the assembly will be leak checked. The getter is held in with a snap ring.

Figure 58 shows the top radiation shield in place. Epoxy is applied to secure it in place. The closure cap (aluminum) is applied to the pressure shell. The joint between the cap and shall will be EB welded and leak checked. The generator will subsequently be evacuated and back-filled with xenon gas to a pressure of about $3 / 4$ of an atmosphere. Following back-fill, the fill tube will be pinched-off and welded. The generator will be tested at several operating environments.

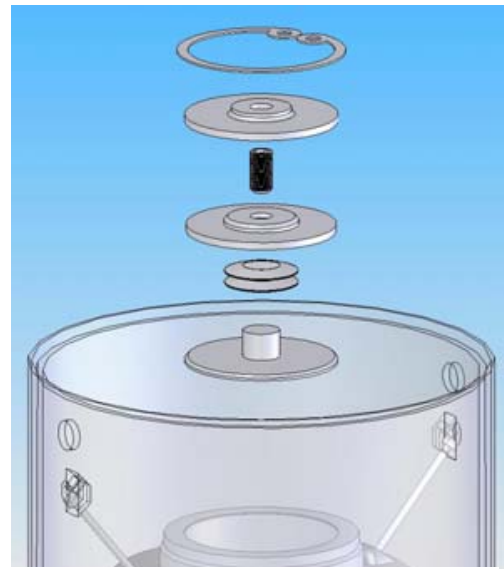

Figure 56. Loading devices for fuel capsule

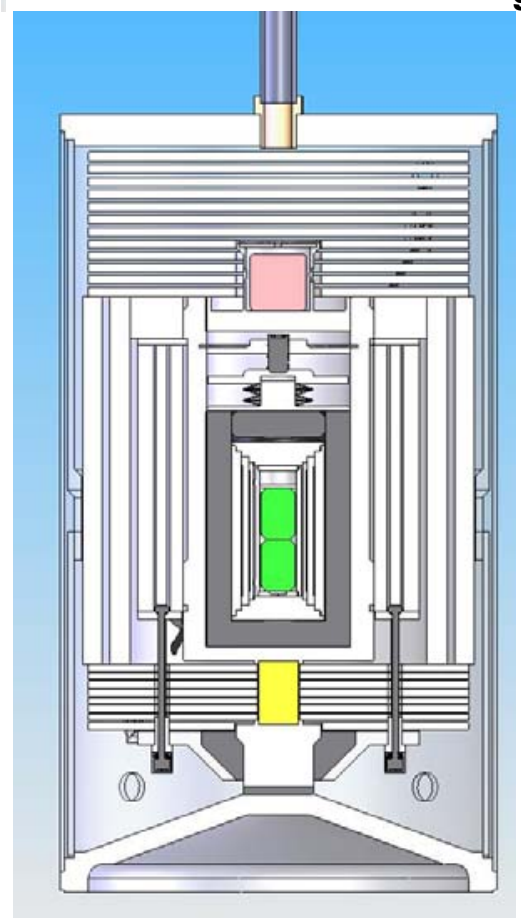

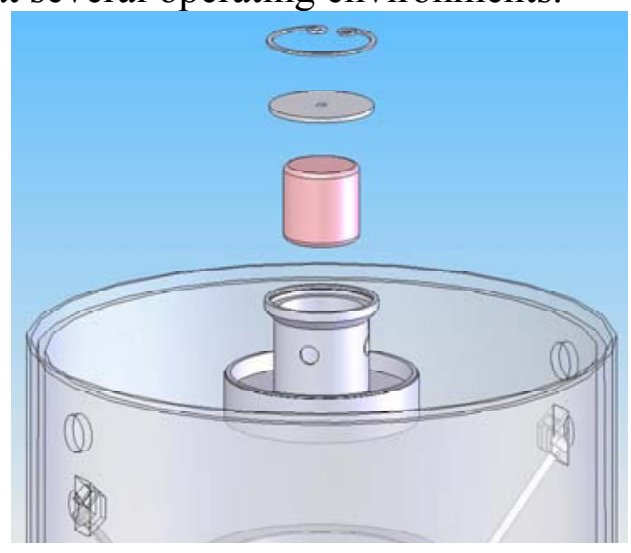

Figure 57. Fuel capsule cap and getter assembly

Figure 58. All radiation shields in place. Cap is welded to pressure shell 


\section{$\underline{\text { RTG Mass }}$}

The CAD system used to draw the $80 \mathrm{~mW}$ generator shown in Figure 58 has a subroutine program that automatically calculates the volume of each component. When the material used to fabricate each component is assigned and the density of each is assigned, the mass of each component is calculated.

The calculated mass for the $80 \mathrm{~mW}$ RTG shown in Table 4 was calculated to be 512.69 grams, not including the mass of the RHU. With the calculated RHU mass of the two fuel capsule version shown in Table 2 of 57.7 grams, the total mass for the 2 Watt RTG with fuel is 570.39 grams.

\section{Table 4. Mass of RTG}

\begin{tabular}{|c|c|}
\hline Mass of Module & 4.65 grams \\
\hline Mass of RTG & 508.04 grams \\
\hline Mass of RHU & 57.7 grams \\
\hline Total Mass & 570.39 \\
\hline
\end{tabular}

\section{Thermal Analysis of mW RPS with Two Stacked Fuel Pellets}

\section{Thermal Model}

A three-dimensional analytical thermal model of the milliwatt space thermoelectric RPS has been completed for the configuration with a $2 \mathrm{~W}_{\mathrm{t}}$ capsule with two stacked clad fuel pellets as shown in Figure 58. All of the significant components of the RPS have been modeled. Due to symmetry, only one fourth of the assembly circumference was modeled. The cross-section of the thermal model is shown in Figure 59 and it includes the TEG module, capsule, graphite shell

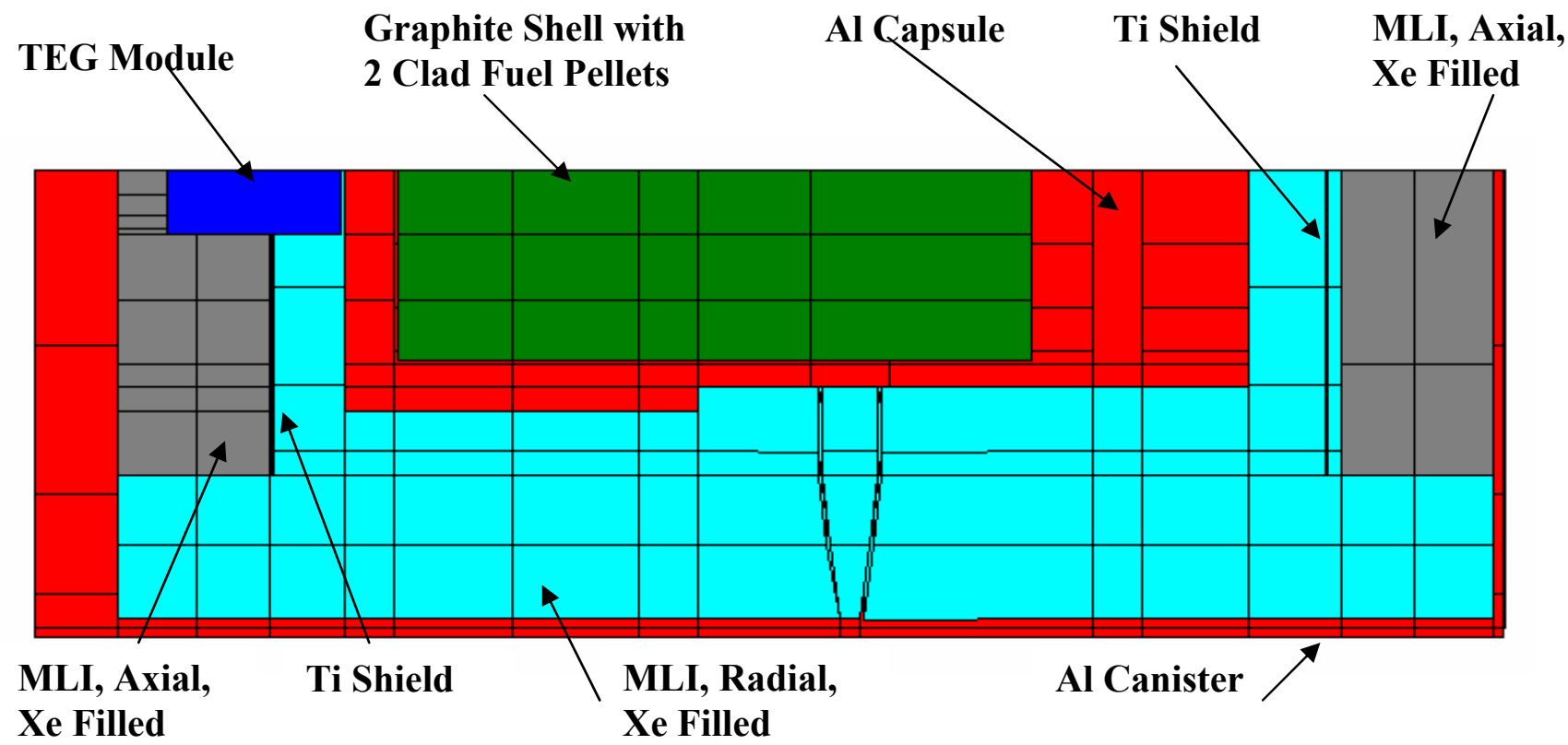

Figure 59. Thermal Model of $2 W_{t}$ RPS with Two Stacked Clad Fuel Pellets 


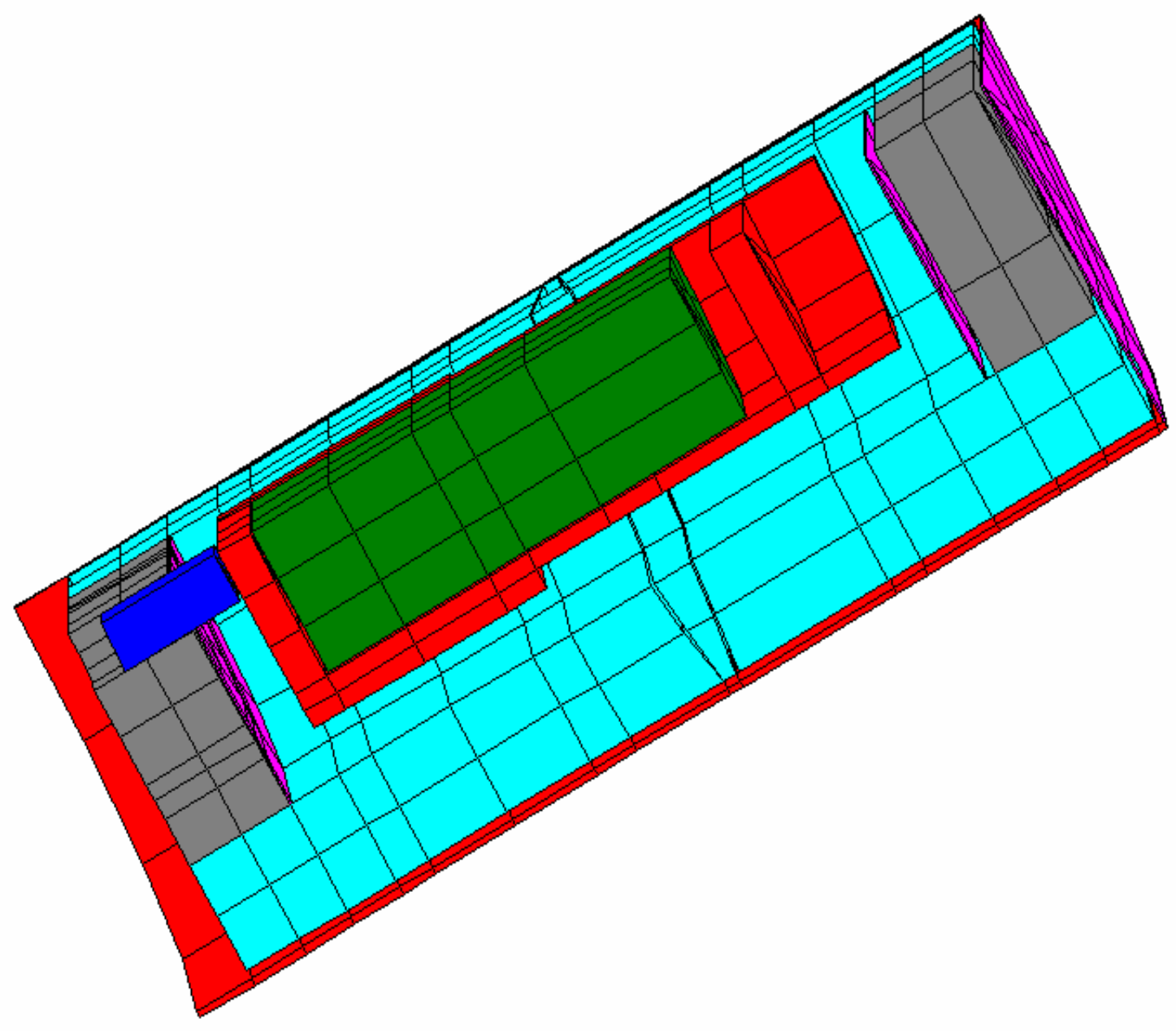

Figure 60. Isometric View of the Thermal Model (1/4 of the Circumference)

with two clad fuel pellets, multi-layer insulation (MLI) back filled with xenon gas, titanium shields, the spacer and the outer canister. Isometric view of the thermal model is shown in Figure 60. Thermal properties for the different materials were taken from standard references, with the radiation properties of the structural materials taken from Reference 4. Thermal properties of xenon gas were taken from Reference 5. This analytical model was generated with the Harvard Thermal Inc. Thermal Analysis System (TAS) computer program (Reference 6) which is now part of the ANSYS system of computer programs.

\section{Thermal Analysis}

The thermal analysis considered the conduction, convection and radiation modes of heat transfer and it was performed with the TAS computer program. In the thermal analyses, the only two prescribed conditions were used: the outside surfaces of the assembly were assumed to be at the ambient temperature of $25^{\circ} \mathrm{C}$, and the heat from the two stacked fuel pellets was used. All other values were calculated. Using the input heat of $0.5 \mathrm{~W}(1 / 4$ of the total heat of $2 \mathrm{~W}$ from the 
two stacked fuel pellets), steady-state thermal analysis was performed. The predicted temperature contours for the milliwatt RPS assembly are shown in Figure 61. The maximum temperature of $379.4^{\circ} \mathrm{C}$ was predicted for the graphite shell with clad fuel pellets. It should be noted that the clad fuel pellets were not modeled in detail because their configuration is not known at this time. Once this information becomes known, the thermal model can be easily made more detailed in this region, yielding detailed temperature distributions in the clad fuel pellets to make sure that their maximum temperature is below their temperature limit.

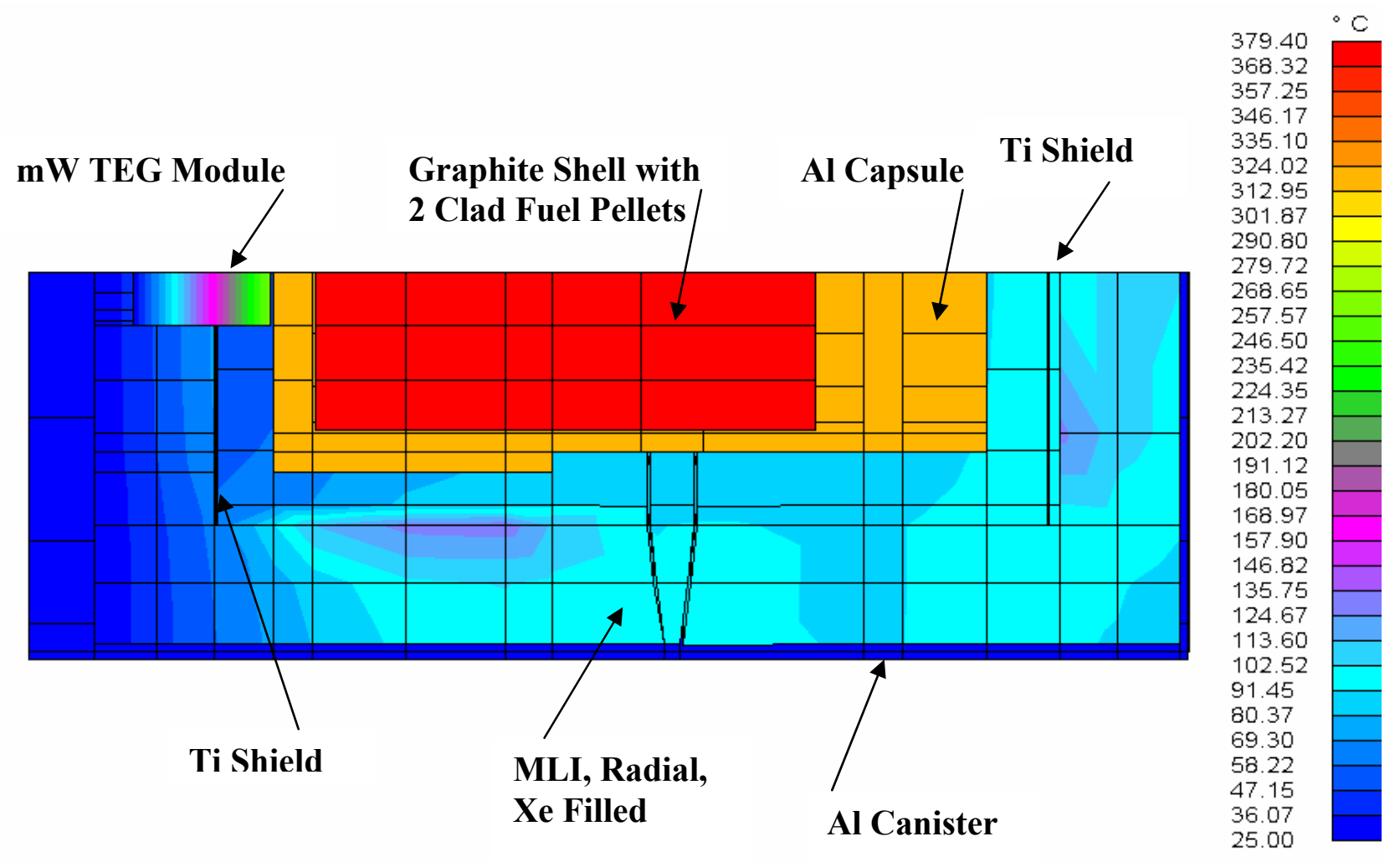

Figure 61. Temperature Contour Plot of $2 \mathrm{~W}_{\mathrm{t}}$ RPS with Two Stacked Clad Fuel Pellets

The temperature distribution in the TEG module is shown in more detail in Figure 62. The predicted hot-side temperature of $260.79^{\circ} \mathrm{C}$ is a little higher than the target value of $250^{\circ} \mathrm{C}$. The heat conducted through the entire TEG module is $1.61 \mathrm{~W}$, which means that 19.5 percent of the total heat of $2 \mathrm{~W}$ is lost to the supporting structure, including the titanium wires, and the environment. This heat loss can be reduced by optimizing the RPS design regarding the thermal insulation.

\section{Design Summary}

Table 5 is a compilation of the dimensions and other specifications of the hi-G compatible milliwatt generator developed for the DOE contract DE-FG07-06ID14755. 


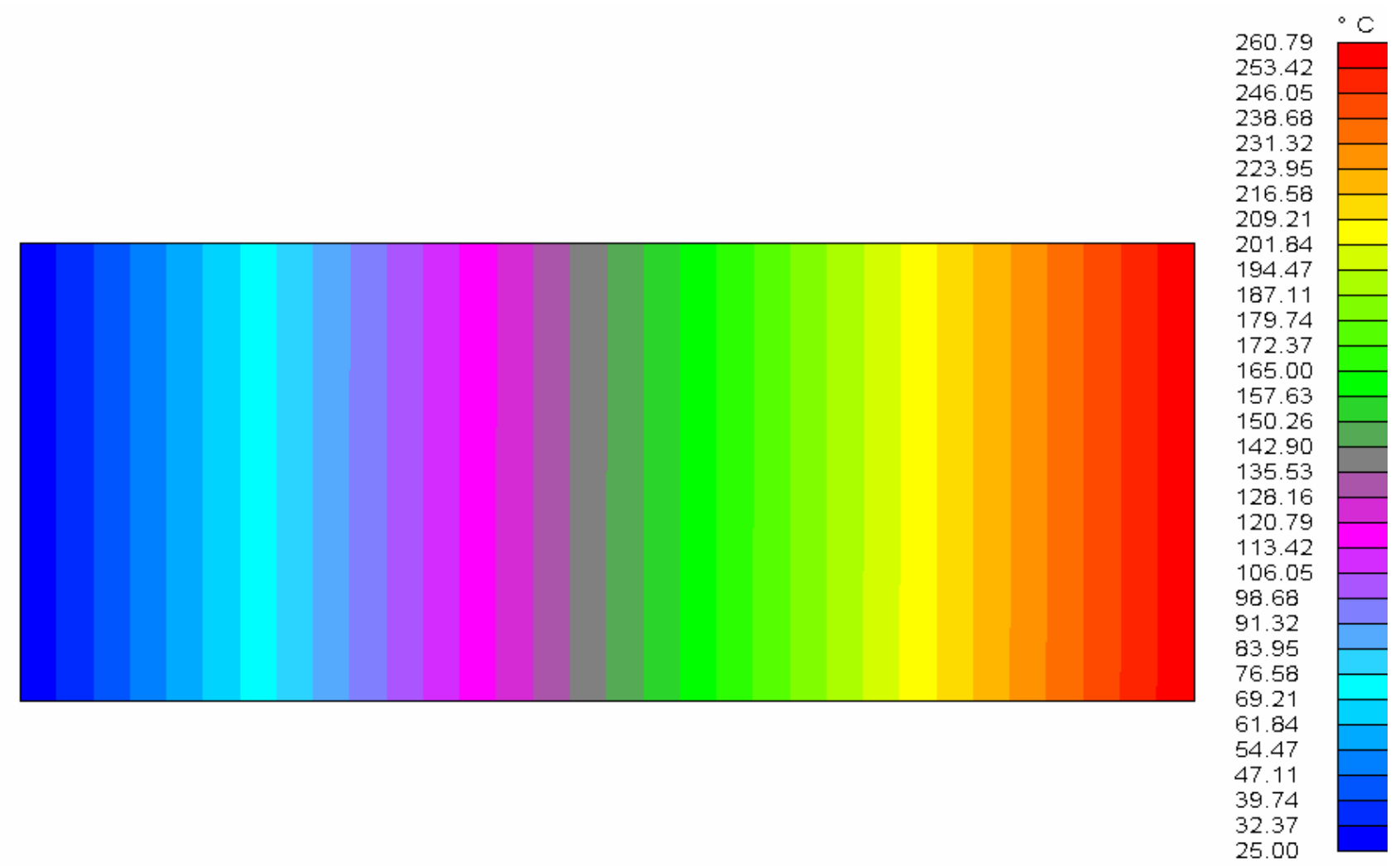

Figure 62. Temperature in TEG Module of $2 W_{t}$ RPS with Two Stacked Clad Fuel Pellets

Table 5. Specifications for the Hi-G Capable MiliWatt RPS

\begin{tabular}{|l|l|}
\hline Power output & $80 \mathrm{~mW}$ BOL \\
\hline Voltage at matched load & $5.5 \mathrm{Volts}$ \\
\hline Fuel & $\mathrm{PuO} 2$ \\
\hline Capsule power & $2 \mathrm{~W}(\mathrm{t}) \mathrm{BOL}$ \\
\hline Heat to cold sink & $1.52 \mathrm{Watts}$ \\
\hline Generator diameter & $7.62 \mathrm{~cm}$ \\
\hline Generator length & $14.5 \mathrm{~cm}$ \\
\hline Thermoelectric parameters & \\
$\mathrm{T}_{\mathrm{H}}$ & $225^{\circ} \mathrm{C}$ \\
$\mathrm{T}_{\mathrm{C}}$ & $25^{\circ} \mathrm{C}$ \\
Material & $\mathrm{BiTe}$ \\
Circuits & 2 \\
Cross connections & 13 \\
\hline Insulation & $\mathrm{MLI}+$ Xenon gas \\
\hline Generator mass & \\
Fuel capsule & 57.7 grams \\
Generator & 512.7 grams \\
Total Mass & 570.4 grams \\
\hline G Loading capability & $5000 \mathrm{G}$ 's \\
\hline Design life & 18 years \\
\hline
\end{tabular}




\section{References}

1. Tate, R.E., "The Light Weight Radioisotope Heater Circuit (LWRHU): A Technical Description of the Reference Design", LA-9078-MS, Los Alamos National Laboratory, January 1982.

2. Wiley, Robert and Robert Carpenter," Small Radioisotope Power Source Concepts", Presented at the Space Technology and Applications International Forum, Albuquerque, NM, February 2004.

3. Bass, J.C., Ghamaty, Saeid, and Morris, Charles, "Design, Fabrication, and Installation of the Energy Harvesting Thermoelectric Generator", Hi-Z Technology, Inc., June 20, 2001, Final Report 2010F under Contract N65549-01-Q-0204.

4. Gubareff, G. G., Janssen, J. E. and Torborg, R. H., Thermal Radiation Properties Survey, Honeywell Research Center, Minneapolis, MN., 1960.

5. Rohsenow, W. M., Hartnett, J. P. and Cho, Y, I. editors, Handbook of Heat Transfer, $3^{\text {rd }}$ Ed., McGraw-Hill Companies, Inc., NY, NY, 1998.

6. Thermal Analysis System User's Manual, Harvard Thermal Inc. Document No. HTTAS:07, Harvard, MA, March 2001. 